CDF'S CHILD, YOUTH, AND FAMILY FUTURES CLEARINGHOUSE

A CONTINUATION

OF THE

ADOLESCENT

PREGNANCY PREVENTION

CLEARINGHOUSE

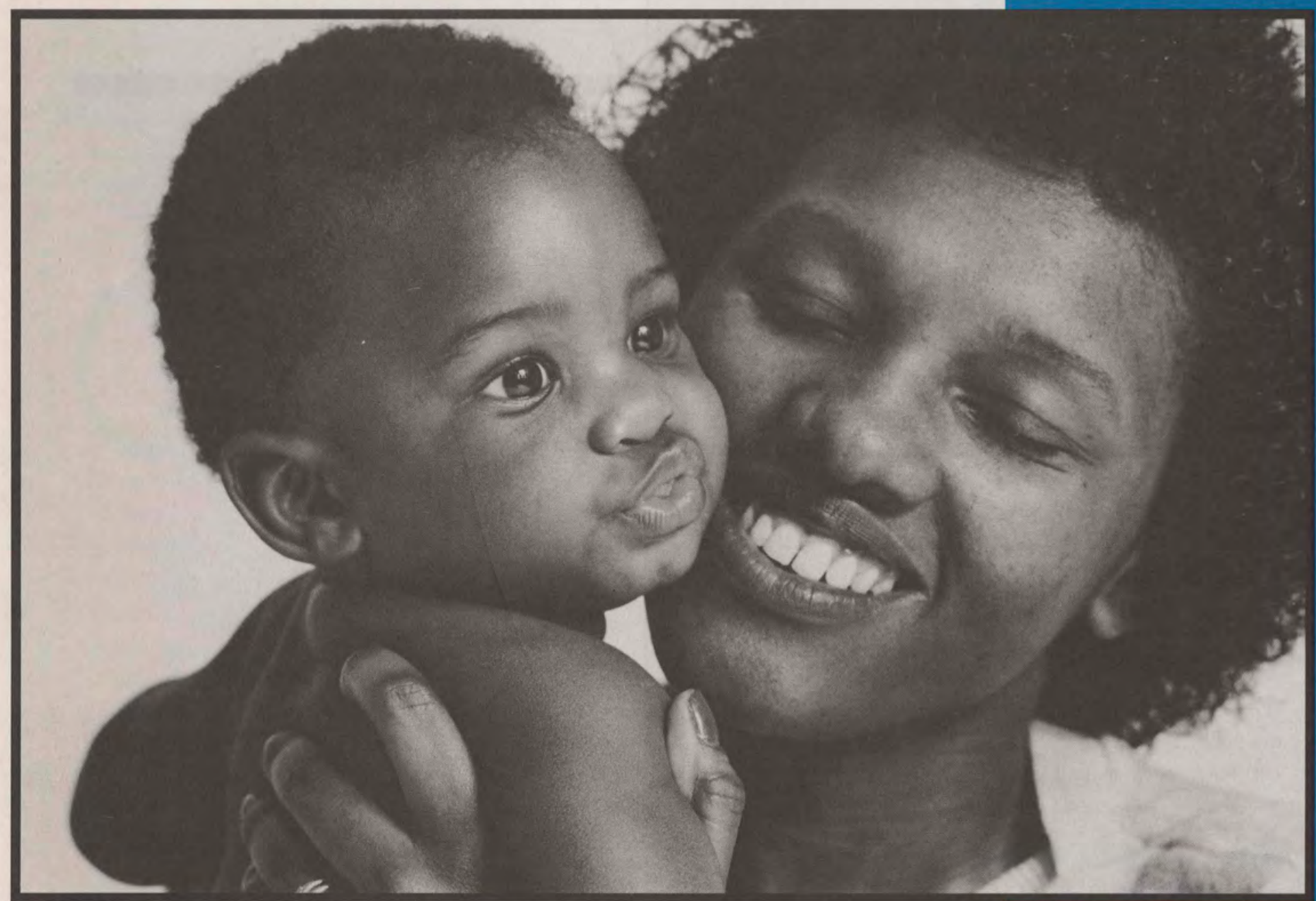

\title{
The Health of America's Children
}

Maternal and child health hasn't improved much in the past 10 years, and probably won't in the near future - until we address the problems that stem from lack of insurance and access to basic health care. 


\section{Acknowledgments}

This report could not have been produced without the efforts of the following people:

Kay Johnson, formerly a member of CDF's Health Division and now with the National March of Dimes.

Melva Edmondson, who entered much of the data contained in this report.

Paul Smith and Janet Simons, from CDF's Research Division, who provided expert statistical guidance and much research guidance.

James Weill, CDF's General Counsel, for his many contributions to both the form and content of the report.

Selma Taffel and Stephanie Ventura from the National Center for Health Statistics (NCHS), who have been so helpful over the years in furnishing us with many of the vital statistics presented in this report.

This report is made possible in part through grants from the William and Flora Hewlett Foundation, Charles Stewart Mott Foundation, Charles H. Revson Foundation, and the John Ben Snow Foundation.

\section{The Health of America's Children}

by

\section{Sara Rosenbaum \\ Christine Layton \\ Joseph Liu}

To purchase additional copies of this report or a one-year subscription (six issues), contact: Publications, Children's Defense Fund, 122 C Street, N.W., Washington, D.C. 20001, (202) 628-8787. Write to the Managing Editor for permission to reprint any part of this publication. The next report will cover family support and parent education programs.

\section{Director of Education, Adolescent Pregnancy Prevention, and Youth Development: Delia Pompa \\ Director of Publications: Donna M. Jablonski \\ Managing Editor: David Heffernan \\ Production Manager: Janis Johnston \\ Administrative Assistant: Stephen Wilhite \\ Children's Defense Fund}

President: Marian Wright Edelman

Executive Vice President: Kati Haycock

Director of Communications: Renee Wessels

General Counsel: James D. Weill

Director of Programs and Policy: Olivia Golden

ISSN:1055-9221

(C)1991, Children's Defense Fund

Design by Robin Foster-Krask, Optima Design, Inc.
EX LIBRIS

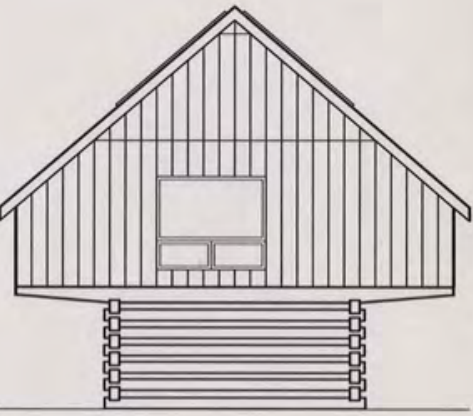

L A NGSTON HUGHES LI B R A R Y

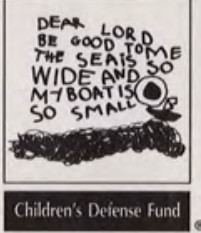

Cover photo by Joe Rubino 


\section{THE HEALH OF AMERICA'S CHILDREN}

\section{Infroduction}

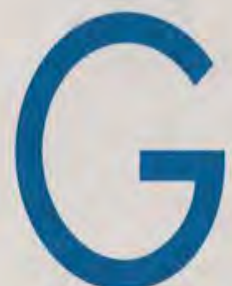

ood health is one of the dreams we all have for our children. Unfortunately, for far too many American children good health is a dream denied or deferred. This seventh edition of The Health of America's

Children presents national, international, state, and city statistics on the health of America's children and the adequacy of programs that serve them. But this report really is about the basic choice that confronts the nation: either invest modest amounts of money now or pay heavily later, as the next generation, diminished by preventable deaths and impaired by preventable disabilities, attempts to meet the demands of the twenty-first century.

In the mightiest nation on earth, nearly 40,000 American children will die in infancy this year. According to the 1989 White House Task Force Report on Infant Mortality, at least 25 percent of infant deaths could be prevented. For every infant who dies, another 10 will be left with permanent disabilities. Twenty-five percent of these disabilities could be prevented, as well. Three in 10 U.S. infants and toddlers go without adequate childhood immunizations and face the nearly unimaginable risk in a civilized society of death and lifelong disability from preventable childhood disease. In the world's wealthiest nation, millions of children go without basic health insurance and without access to basic health services.

Underlying these shameful statistics is pervasive childhood poverty. Childhood death, illness, and disability are social phenomena, and social factors lie at the heart of the nation's poor child health performance. In 1989 poverty claimed one in five chil- dren, one in four children younger than six, one in three children living with parents younger than 30 , and nearly one in two black and Latino children. That year an astonishing one in 11 American children younger than six lived in families with incomes of less than 50 percent of the federal poverty level.

Poverty affects child health in two ways. First, poverty exposes children to living conditions that threaten their health. Inadequate housing, sanitation, food, and medical care all are associated with poverty and all have a major impact on child health.

Second, poverty deprives families of the resources they need to cope with childhood illness and disability when it does strike. Poor children are significantly more likely to be born at low birthweight (which accounts for 60 percent of all infant deaths) and are at heightened risk for a host of preventable child health problems. Poor families are far more likely to be uninsured, and are far more likely to live in areas with too few affordable health care services. As a result, health problems affecting poor children are significantly more likely to be serious and to have lifelong consequences.

Given the relationship between childhood poverty and health status, it should be no surprise that a decade that witnessed an increase of more than 2 million in the number of poor children and major cuts in social and health programs for low-income children and families also saw major erosion in basic maternal and child health indicators such as infant low birthweight and prenatal care. It should surprise no one that childhood immunization rates plummeted or that the incidence of communicable disease soared. And it should come as no great shock that the U.S. infant mortality rate, like its childhood poverty rate, lags behind other industrialized nations. 


\section{OVERVIEW OF KEY FINDINGS}

\section{Infant Mortality}

In $1988,38,910$ infants in this nation died before reaching their first birthday. Nearly one in 100 American babies did not survive infancy. The U.S. infant mortality rate ranked behind 18 other nations, including Hong Kong, Singapore, and Spain. For only the second time since 1965 , there was no statistically significant improvement in the national infant mortality rate from the previous year. During the 1980 s, infant mortality improved at a pace one-third slower than during the previous decade.

The plight of black infants is even bleaker. In 1988 black infants were more than twice as likely as white infants to die within the year after birth. The gap between black and white infant mortality in 1988 stood at its widest point since race specific data were first recorded by the federal government in 1940 . Since 1940 the gap has caused the deaths of nearly 415,000 black infants who would not have died if the black infant mortality rate were as low as the white rate.

\section{Low Birthweight}

The single leading cause of infant death is low birthweight. More than 270,000 newborns were born too soon or too small in 1988 . While the incidence of low birthweight fell slightly among whites, the rate increased for blacks. The percentage of black infants born at low birthweight rose to 13 percent in 1988 , the highest level since 1976.

\section{Mafernal Mortality}

Not only is infant health at risk, but more women are dying from complications related to pregnancy. The maternal mortality rate jumped 27 percent between 1987 and 1988. This rise in maternal mortality was the largest one-year increase in the past half-century.

\section{Prenatal Care}

Prenatal care that begins early and continues throughout pregnancy can prevent low birthweight and infant and maternal mortality. In 1988 less than 76 percent of all infants were born to mothers who received prenatal care within the first three months of pregnancy, worse than the previous year and no better than the levels recorded in 1979. Black and Mexican American infants were far less likely to be born to mothers who received early prenatal care -61 percent and 58 percent, respectively.

Even more disturbing is the steadily increasing proportion of women who received no prenatal care or none until the last three months of pregnancy. In every year in the 1980 s the late or no prenatal care rate worsened or did not improve. In 1988 more than 6 percent of all births were to women who received late or no prenatal care. The late or no care rates among black and Latino births were nearly twice as high.

Prenatal care must begin early and include a sufficient number of visits to be considered adequate. In 1988 less than 69 percent of all births were to women who received adequate prenatal care. More than 250,000 infants were born to women whose prenatal care was considered inadequate. Among black births, barely 50 percent were to mothers whose care could be considered minimally adequate. 


\section{Teen Births}

Births to teenage girls remain a serious problem. The white birth rate to girls ages 15 to 19 stood at the highest level since 1982. For black teens, the 1988 birth rate was at its highest point since 1975 , with nearly 106 births to teen mothers for every 1,000 black teenage girls.

\section{Immunizations}

Among many disheartening recent health trends is the astonishing collapse in our nation's ability to protect children against preventable diseases. In 1990 well over 25,000 cases of measles were reported. More children died from measles that year than in any year since 1971. Key factors in the current measles epidemic are growing childhood poverty, skyrocketing vaccine costs, inadequate public investment in immunization programs, and a fraying and underfunded public health system. More than 70 percent of community health centers experience vaccine shortages.

\section{Healfh Insurance}

Too often, families cannot get the health care they need because they do not have insurance. Only 83 percent of all children had either public or private health coverage in 1988. Infants, Latinos, and children in families with annual incomes of less than $\$ 25,000$ were least likely to have health coverage. In addition, recent data show that 9 million women of childbearing age were completely uninsured and 5 million were uncovered for maternity care.

\section{Objectives for the Year 2000}

In 1990 the U.S. Public Health Service established national health objectives for the year 2000 . The new objectives build on goals for 1990 established by the Surgeon General in 1979. The year 2000 objectives are a testament to stagnating rates of improvement in maternal and child health indicators. For example, the year 2000 objectives for low birthweight, prenatal care, and immunizations are identical to the 1990 goals that were not met.

At current rates of progress many of the goals relating to maternal and child health will not be met for decades, and in some cases, centuries. For example, the objective of reducing the low-birthweight rate to less than 5 percent of all births will not be met until the year 2083. Similarly, the goal that 90 percent of all women begin prenatal care in the first trimester will not be reached until 2129. If black women are considered alone, then the prenatal objective will not be reached until 2309. Since vaccination rates are worsening, unless the trend is reversed, the goal of protecting 90 percent of all children against preventable diseases never will be met.

\section{State-by-State Data}

A series of rankings and trend tables showing state-bystate maternal and infant health indicators for 1988 and for the 1978-1988 period is available as a separate Appendix to this report. Contact CDF Publications for ordering information. 
Table 1

\section{UNITED STATES FACT SHEET, 1988}

\begin{tabular}{rrrr}
\multicolumn{1}{c}{ White } & \multicolumn{1}{c}{ Nonwhite } & \multicolumn{1}{c}{ Total } \\
\hline & \multicolumn{1}{c}{ Black } & Total & \\
& & & \\
$3,046,162$ & 671,976 & 863,348 & $3,909,510$ \\
319,544 & 152,508 & 169,397 & 488,941 \\
4,073 & 6,182 & 6,515 & 10,588
\end{tabular}

\section{Births to Unmarried Women}

As percentage of all births

To all women

$17.7 \%$

$63.5 \%$

$53.9 \%$

$25.7 \%$

To women age 19 and younger

53.5

91.2

88.3

\section{Low-Birthweight Births}

Percentage of births that were low birthweight

To all women

To women age 19 and younger

\section{Birth Rates to Girls Ages 15 to 19}

Births per 1,000 girls

105.9

95.3

\section{Prenatal Care}

Percentage of babies born to women who:

Began prenatal care in the first trimester
All women
$79.4 \%$

$61.1 \%$

$63.6 \%$

$75.9 \%$

Women age 19 and younger

Began prenatal care in the third trimester or not at all
All women
$5.0 \%$

Women age 19 and younger

11.7

$10.9 \%$

$10.1 \%$

$6.1 \%$

15.2

15.1

Received adequate prenatal care

All women

$73.5 \%$

$50.7 \%$

$52.1 \%$

$68.9 \%$

Received inadequate prenatal care

All women

$6.1 \%$

$15.5 \%$

$14.8 \%$

$8.0 \%$

\section{Infant Mortality}

Infant deaths per 1,000 live births

Total infant deaths

8.5

17.6

15.0

10.0

Neonatal deaths

Postneonatal deaths 


\section{National and International Findings}

\section{Births by Age and Race of Mother}

n 1988 a total of 3,909,510 infants were born (Table 1). Seventy-eight percent of all births were to white mothers, while 17.2 percent were to black mothers. A total of 488,941 births (12.5 percent of all births) were to women younger than 20. About 0.25 percent were to girls younger than 15.

In 1988 births to white women younger than 20 represented 10.5 percent of all white births. Births to black women in that age group represented 22.7 percent of all black births that year, a proportion more than twice as great. Births to white and black

Table 2

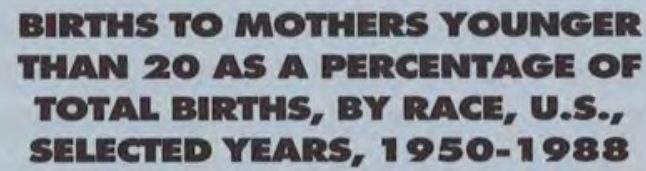

\begin{tabular}{|c|c|c|c|c|}
\hline \multirow[b]{2}{*}{ Year } & \multirow[b]{2}{*}{ All Races } & \multirow[b]{2}{*}{ White } & \multicolumn{2}{|c|}{ Nonwhite } \\
\hline & & & Black & Total \\
\hline 1950 & $11.9 \%$ & $10.5 \%$ & $21.7 \%$ & $21.2 \%$ \\
\hline 1955 & 12.1 & 10.8 & 19.1 & 19.6 \\
\hline 1960 & 13.9 & 12.8 & - & 20.3 \\
\hline 1961 & 14.3 & 13.2 & - & 20.2 \\
\hline 1962 & 14.6 & 13.6 & - & 20.6 \\
\hline 1963 & 14.5 & 13.4 & - & 21.2 \\
\hline 1964 & 14.7 & 13.3 & 23.1 & 22.3 \\
\hline 1965 & 15.9 & 14.3 & 25.2 & 24.0 \\
\hline 1966 & 17.5 & 15.6 & 27.8 & 26.4 \\
\hline 1967 & 17.2 & 15.0 & 20.5 & 27.9 \\
\hline 1968 & 17.2 & 14.8 & 30.9 & 29.1 \\
\hline 1969 & 17.1 & 14.6 & 31.0 & 29.2 \\
\hline 1970 & 17.6 & 15.1 & 31.3 & 29.5 \\
\hline 1971 & 18.0 & 15.4 & 31.7 & 29.7 \\
\hline 1972 & 19.3 & 16.5 & 33.8 & 31.5 \\
\hline 1973 & 19.7 & 16.8 & 34.4 & 32.0 \\
\hline 1974 & 19.2 & 16.5 & 33.9 & 31.3 \\
\hline 1975 & 18.9 & 16.3 & 32.9 & 30.3 \\
\hline 1976 & 18.0 & 15.5 & 31.2 & 28.7 \\
\hline 1977 & 17.2 & 14.7 & 29.7 & 27.3 \\
\hline 1978 & 16.6 & 14.3 & 28.5 & 26.0 \\
\hline 1979 & 16.0 & 13.8 & 27.5 & 25.1 \\
\hline 1980 & 15.6 & 13.5 & 26.5 & 23.8 \\
\hline 1981 & 14.8 & 12.9 & 25.3 & 22.6 \\
\hline 1982 & 14.2 & 12.3 & 24.6 & 21.9 \\
\hline 1983 & 13.7 & 11.8 & 24.3 & 21.4 \\
\hline 1984 & 13.0 & 11.1 & 23.6 & 20.8 \\
\hline 1985 & 12.7 & 10.8 & 23.0 & 20.1 \\
\hline 1986 & 12.6 & 10.6 & 22.8 & 19.9 \\
\hline 1987 & 12.4 & 10.6 & 22.6 & 19.6 \\
\hline 1988 & 12.5 & 10.5 & 22.7 & 19.6 \\
\hline
\end{tabular}

girls younger than 15 represented 0.1 percent and 0.9 percent, respectively, of all births that year.

While black infants made up slightly more than 17 percent of all births in 1988, they constituted 31.2 percent of all births that year to women younger than 20 and 58.4 percent of all births to girls younger than 15 . When all nonwhite births are considered, nonwhite infants constituted 34.6 percent of all babies born to women younger than 20 and 61.5 percent of all infants born to girls younger than 15 .

\section{Trends in Births to Young Women, by Race}

The proportion of all births that were to women younger than 20 in 1988 stood at 12.5 percent. With the exception of 1987 , the percent of all U.S. births that are to teens has not been this low since 1955 (Table 2). However, the birth rate for 15 - through

Table 3

\section{BIRTH RATES* TO GIRLS AGES I5 TO 19, BY RACE, 1960-1988}

\begin{tabular}{|c|c|c|c|c|}
\hline Year & All Races & White & Black & Nonwhite \\
\hline 1960 & 89.1 & 79.4 & 156.1 & 158.2 \\
\hline 1961 & 88.6 & 79.2 & 155.2 & 155.2 \\
\hline 1962 & 81.4 & 73.2 & 147.1 & 147.1 \\
\hline 1963 & 76.7 & 68.2 & 142.6 & 142.6 \\
\hline 1964 & 73.1 & 63.4 & 147.6 & 141.5 \\
\hline 1965 & 70.5 & 60.6 & 144.6 & 138.4 \\
\hline 1966 & 70.3 & 60.4 & 142.7 & 136.4 \\
\hline 1967 & 67.5 & 56.9 & 141.8 & 135.0 \\
\hline 1968 & 65.6 & 54.9 & 138.7 & 132.3 \\
\hline 1969 & 65.5 & 54.7 & 137.0 & 131.3 \\
\hline 1970 & 68.3 & 57.4 & 140.7 & 133.4 \\
\hline 1971 & 64.5 & 53.6 & 134.5 & 128.5 \\
\hline 1972 & 61.7 & 51.0 & 129.8 & 123.8 \\
\hline 1973 & 59.3 & 49.0 & 123.1 & 117.5 \\
\hline 1974 & 57.5 & 47.9 & 116.5 & 111.3 \\
\hline 1975 & 55.6 & 46.4 & 111.8 & 106.4 \\
\hline 1976 & 52.8 & 44.1 & 104.9 & 99.9 \\
\hline 1977 & 52.8 & 44.1 & 104.7 & 99.5 \\
\hline 1978 & 51.5 & 42.9 & 100.9 & 96.0 \\
\hline 1979 & 52.3 & 43.7 & 101.7 & 96.5 \\
\hline 1980 & 53.0 & 44.7 & 100.0 & 94.6 \\
\hline 1981 & 52.7 & 44.6 & 97.1 & 91.8 \\
\hline 1982 & 52.9 & 44.6 & 97.0 & 91.5 \\
\hline 1983 & 51.7 & 43.6 & 95.5 & 89.3 \\
\hline 1984 & 50.9 & 42.5 & 95.7 & 89.0 \\
\hline 1985 & 51.3 & 42.8 & 97.4 & 89.7 \\
\hline 1986 & 50.6 & 41.8 & 98.1 & 89.7 \\
\hline 1987 & 51.1 & 41.9 & 100.3 & 90.9 \\
\hline 1988 & 53.6 & 43.7 & 105.9 & 95.3 \\
\hline \multicolumn{5}{|c|}{$\begin{array}{l}\text { The birth rate is the number of live births per } 1,000 \text { women in a } \\
\text { specified group. }\end{array}$} \\
\hline \multicolumn{5}{|c|}{ SOURCE: National Center for Health Statistics. } \\
\hline
\end{tabular}


Figure 1
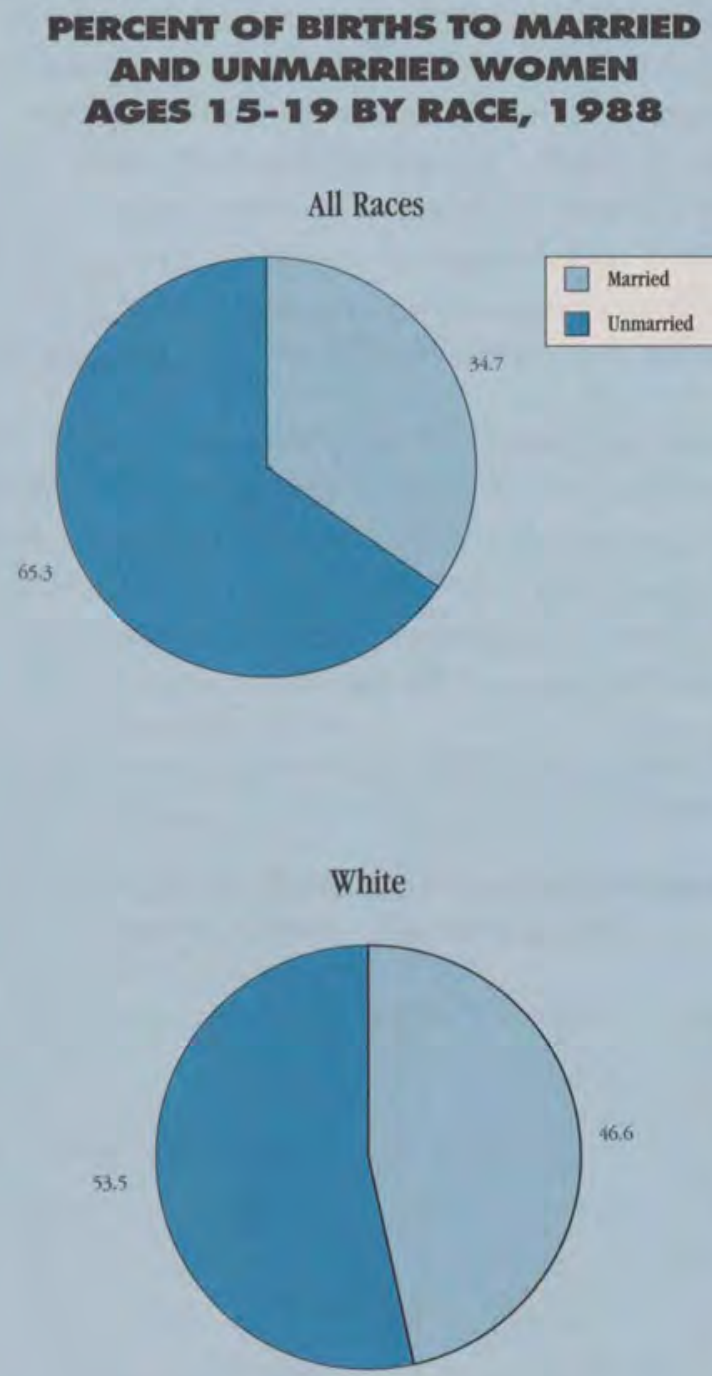

Black

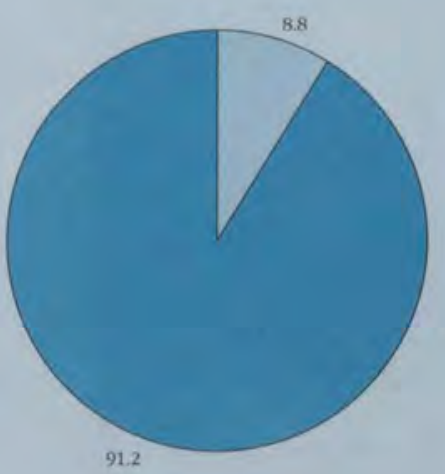

SOURCE: National Center for Health Statistics. 19-year-olds rose between 1987 and 1988 (Table 3). ${ }^{1}$ This means that even a larger proportion of all 1988 births would have occurred to women younger than 20 had birth rates for older mothers not also increased. For white teens ages 15 through 19 the 1988 birth rate of 43.7 per 1,000 women of that age was the highest since 1982. For black women in the age group, the 1988 birth rate of 105.9 births per 1,000 women stood at its highest point since $1975 .{ }^{2}$

Of all births to women in 1988, 25.7 percent were to unmarried women. ${ }^{3}$ Among women ages 15 through $19,65.3$ percent of all 1988 births were to unmarried women. Among white 15- through 19year-olds, 53.5 percent were to unmarried women. Among nonwhite and black 15-through 19-yearolds, the proportions were 88.3 percent and 91.2 percent, respectively (Figure 1). ${ }^{4}$

The proportion of all U.S. births to teens is falling as the number of women in the age group shrinks. But for teenage mothers of all races, unmarried childbearing has become the norm. Childbearing during adolescence (to married or unmarried teens) is associated closely with low educational attainment and a lack of basic skills. It is these two factors, rather than race or ethnicity, that are most heavily determinative of teenage childbearing. ${ }^{5}$

Adolescent childbearing dramatically increases the risk of long-term poverty for teenage mothers and their infants. For this reason, even a slight increase in birth rates among teenage women should be viewed with concern.

\section{Births to Latino Mothers*}

Thirty states and the District of Columbia reported the Latino origin of parents on 1988 birth certificates. The number of Latino births in these jurisdictions totaled 449,604 (Table 4). Of these births, 16.4 percent were to women younger than 20 and 0.4 percent were to girls younger than 15 . In these 31 jurisdictions, births to teens of all origins represented 12.7 percent of births, while births to girls younger than 15 represented 0.3 percent.

As in prior years, the 1988 childbirth statistics indicate distinct variations in childbearing patterns by race and ethnicity. Black non-Latino infants are

- Latino here refers to people with ancestral ties to Latin America, Spain, and other Spanish-speaking countries. Most data reporting sources use the term Hispanic. There is no difference between the use of "Latino" here and data sources' use of "Hispanic." 
significantly more likely than white non-Latino infants to be born to young mothers and are substantially more likely to have extremely young mothers (younger than 15). Latino infants also tend to be born to young mothers, although young childbearing is not nearly as pronounced for Latino women as a whole as it is among black, non-Latino women.

\section{Low Birthweight and Prematurity}

In 1988, 270,681 infants were born at low birthweight (weighing less than 5.5 pounds at birth). The proportion of infants born at low birthweight in 1988 ( 6.9 percent of all live births) was the same as in 1987 and identical to the percentage born at low birthweight in 1979 (Table 5). After falling from 1979 to 1984 , the overall rate increased between 1984 and 1988. Among white infants the proportion born at low birthweight declined slightly between 1987 and 1988, from 5.7 percent to 5.6 percent of all live births. For black and nonwhite infants, however, the proportions increased. In 1988, 13 percent of all black infants were born at low birthweight a 2.4 percent increase over 1987 levels and the highest proportion since 1976. Among Latino infants in the 31 reporting jurisdictions, 6.2 percent were born at low birthweight, although these numbers ranged from 5.6 percent to 9.4 percent, depending on the national origin of the mother (Table 7).

In 1988 , as in $1987,1.24$ percent of all infants were born at very low birthweight (less than 3.5 pounds at birth). In every year in the 1980 s very low birthweight rates got worse or did not improve. While a slight decline in the incidence of very low birthweight births occurred among white infants in 1988 , the proportion of black infants born at very low birthweight increased (Table 6).

By 1988 the low birthweight and very low birthweight "gaps" between white and black infants stood at unprecedented levels. In 1988 a black infant was 2.32 times more likely than a white infant to be born at low birthweight and 2.99 times more likely to be born at very low birthweight. The black/white low birthweight gap in 1988 was the widest since the National Center for Health Statistics began reporting low-birthweight data by race in 1969.

Prematurity (birth before the thirty-seventh week of pregnancy) is closely associated with low birthweight. Approximately 40 percent of all infants born prematurely are low birthweight, compared with only 3 percent of infants not born until the

Table 4

\section{LATINO NATALTY, 30 REPORTING STATES* AND THE DISTRIG OF COLUMBIA, 1988}

\begin{tabular}{|c|c|c|c|c|c|c|c|c|c|}
\hline \multirow[b]{2}{*}{ Births } & \multicolumn{6}{|c|}{ Latino } & \multicolumn{2}{|c|}{ Non-Latino } & \multirow[t]{2}{*}{ All Origins } \\
\hline & Total & Mexican & $\begin{array}{c}\text { Puerto } \\
\text { Rican }\end{array}$ & Cuban & $\begin{array}{l}\text { Central } \\
\text { and South } \\
\text { American }\end{array}$ & $\begin{array}{l}\text { Other } \\
\text { Latino }\end{array}$ & White & Black & \\
\hline To all women & 449,604 & 271,170 & 46,232 & 10,189 & 57,610 & 64,403 & $1,652,782$ & 455,883 & $2,856,492$ \\
\hline To women age 19 and younger & 73,858 & 46,841 & 9,886 & 619 & 4,662 & 11,850 & 160,361 & 104,200 & 362,308 \\
\hline To girls younger than 15 & 1,621 & 1,021 & 243 & 14 & 86 & 257 & 1,585 & 4,300 & 7.951 \\
\hline \multicolumn{10}{|l|}{ Teen Births } \\
\hline To women age 19 and younger & $16.4 \%$ & $17.3 \%$ & $21.4 \%$ & $6.1 \%$ & $8.1 \%$ & $18.4 \%$ & $9,7 \%$ & $22.9 \%$ & $12.7 \%$ \\
\hline To girls younger than 15 & $0.4 \%$ & $0.4 \%$ & $0.5 \%$ & $0.1 \%$ & $0.1 \%$ & $0.4 \%$ & $0.1 \%$ & $0.9 \%$ & $0.3 \%$ \\
\hline \multicolumn{10}{|c|}{$\begin{array}{l}\text { Prenatal Care } \\
\text { Percentage of babies born to women who: }\end{array}$} \\
\hline Received early prenatal care & $61.3 \%$ & $58.3 \%$ & $63.2 \%$ & $83.4 \%$ & $62.8 \%$ & $67.3 \%$ & $82.0 \%$ & $60.8 \%$ & $75.0 \%$ \\
\hline Received late or no prenatal care & $12.1 \%$ & $13.9 \%$ & $10.2 \%$ & $3.6 \%$ & $9.9 \%$ & $8.8 \%$ & $4.1 \%$ & $10.9 \%$ & $6.5 \%$ \\
\hline
\end{tabular}

- See Technical Notes for a listing of states.

SOURCE: National Center for Health Statistics. Calculations by the Children's Defense Fund. 
Table 5

PERCENTAGE OF INFANTS BORN AT LOW BIRTHWEIGHT, BY RACE, U.S., SELECTED YEARS, 1950-1988

\begin{tabular}{|c|c|c|c|c|c|}
\hline \multirow[b]{2}{*}{ Year } & \multirow{2}{*}{$\begin{array}{c}\text { All } \\
\text { Races }\end{array}$} & \multirow[b]{2}{*}{ White } & \multicolumn{2}{|c|}{ Nonwhite } & \multirow{2}{*}{$\begin{array}{l}\text { Ratio of } \\
\text { Black to } \\
\text { White }\end{array}$} \\
\hline & & & Black & Total & \\
\hline 1950 & $7.5 \%$ & $7.1 \%$ & - & $10.2 \%$ & - \\
\hline 1955 & 7.6 & 6.8 & - & 11.7 & - \\
\hline 1960 & 7.7 & 6.8 & - & 12.8 & - \\
\hline 1961 & 7.8 & 6.9 & - & 13.0 & - \\
\hline 1962 & 8.0 & 7.0 & - & 13.1 & - \\
\hline 1963 & 8.2 & 7.1 & - & 13.6 & - \\
\hline 1964 & 8.2 & 7.1 & - & 13.9 & - \\
\hline 1965 & 8.3 & 7.2 & - & 13.8 & - \\
\hline 1966 & 8.3 & 7.2 & - & 13.9 & - \\
\hline 1967 & 8.2 & 7.1 & - & 13.6 & - \\
\hline 1968 & 8.2 & 7.1 & - & 13.7 & - \\
\hline 1969 & 8.1 & 7.0 & $14.1 \%$ & 13.5 & 2.01 \\
\hline 1970 & 7.9 & 6.8 & 13.9 & 13.3 & 2.04 \\
\hline 1971 & 7.7 & 6.6 & 13.4 & 12.7 & 2.03 \\
\hline 1972 & 7.7 & 6.5 & 13.6 & 12.9 & 2.09 \\
\hline 1973 & 7.6 & 6.4 & 13.3 & 12.5 & 2.08 \\
\hline 1974 & 7.4 & 6.3 & 13.1 & 12.4 & 2.08 \\
\hline 1975 & 7.4 & 6.3 & 13.1 & 12.2 & 2.08 \\
\hline 1976 & 7.3 & 6.1 & 13.0 & 12.1 & 2.13 \\
\hline 1977 & 7.1 & 5.9 & 12.8 & 11.9 & 2.17 \\
\hline 1978 & 7.1 & 5.9 & 12.8 & 11.9 & 2.17 \\
\hline 1979 & 6.9 & 5.8 & 12.6 & 11.6 & 2.17 \\
\hline 1980 & 6.8 & 5.7 & 12.5 & 11.5 & 2.19 \\
\hline 1981 & 6.8 & 5.7 & 12.5 & 11.4 & 2.19 \\
\hline 1982 & 6.8 & 5.6 & 12.4 & 11.2 & 2.21 \\
\hline 1983 & 6.8 & 5.6 & 12.6 & 11.2 & 2.25 \\
\hline 1984 & 6.7 & 5.6 & 12.4 & 11.1 & 2.21 \\
\hline 1985 & 6.8 & 5.6 & 12.4 & 11.1 & 2.21 \\
\hline 1986 & 6.8 & 5.6 & 12.5 & 11.2 & 2.23 \\
\hline 1987 & 6.9 & 5.7 & 12.7 & 11.3 & 2.23 \\
\hline 1988 & 6.9 & 5.6 & 13.0 & 11.5 & 2.32 \\
\hline
\end{tabular}

SOURCE: National Center for Health Statistics. Calculations by the Children's Defense Fund.

Table 6

PERCENTAGE OF INFANTS BORN AT VERY LOW BIRTHWEIGHT, BY RACE, U.S., 1979-1988

$\begin{array}{lcll}\text { Year } & \text { All Races } & \text { White } & \text { Black } \\ 1979 & 1.15 \% & 0.90 \% & 2.37 \% \\ 1980 & 1.15 & 0.90 & 2.44 \\ 1981 & 1.16 & 0.90 & 2.47 \\ 1982 & 1.18 & 0.92 & 2.51 \\ 1983 & 1.19 & 0.93 & 2.55 \\ 1984 & 1.19 & 0.92 & 2.56 \\ 1985 & 1.21 & 0.94 & 2.65 \\ 1986 & 1.21 & 0.93 & 2.66 \\ 1987 & 1.24 & 0.94 & 2.73 \\ 1988 & 1.24 & 0.93 & 2.78\end{array}$

SOURCE: National Center for Health Statistics, Calculations by the Children's Defense Fund. thirty-eighth week. In 1987 and 1988 the proportion of infants born prematurely stood at 10.2 percent of all live births, an 8.5 percent increase from the 1981 level of 9.4 percent. Among white infants the 1988 proportion of births that were preterm ( 8.5 percent) was identical to 1987 . For black infants, the proportion born prematurely rose from 18.0 percent to 18.3 percent. The black/white prematurity disparity in 1988 stood at 2.15 -to- 1 - nearly as wide as the low birthweight disparity.

Infants born at low birthweight make up less than 7 percent of all live births but nearly 60 percent of all infant deaths, according to the U.S. Public Health Service ${ }^{6}$ Infants born too soon are far more likely to be born too small and far more likely to die. Low birthweight and prematurity are problems that disproportionately affect black infants and that overwhelmingly account for the grave and growing racial disparities in infant mortality by race. While low birthweight is a lesser problem for some Latino subpopulations, for others the incidence of low birthweight approaches that of black infants.

During the 1970 s small but significant improvements in low birthweight occurred, with a 16.0 percent decline in the incidence of low birthweight from 1969 to 1980 . However, by 1988 the overall incidence of low birthweight had increased from its 1980 level of 6.8 percent.

Low birthweight is not only the leading killer of infants, it is also a primary source of lifelong disability. Infants born at low birthweight (particularly those born at very low birthweight) are significantly more likely to suffer such lifelong disabilities as mental retardation, cerebral palsy, vision and hearing disabilities, and other problems. Low birthweight is closely associated with poverty, poor living conditions, and inadequate access to medical care before and during pregnancy.

The United States leads the world in its capacity to save very tiny infants from death and disability through the use of intensive care technology. ${ }^{7}$ But the United States also leads most industrialized nations in the high proportion of infants born at low birthweight. During the 1980 to 1988 period the United States ranked twenty-eighth in the proportion of low-birthweight births, worse than the rates of Greece and the Soviet Union and tied with Chile and Paraguay (Table 8). 


\section{Access to Prenatal Care}

One of the most important factors associated with healthy births and low infant mortality is early, continuous, and comprehensive care throughout pregnancy and delivery. Maternity care should begin early with a planned pregnancy and continue throughout pregnancy, and should include both prenatal care and services for conditions that can complicate or that arise from pregnancy. Maternity care has been shown to be particularly effective in the case of low-income women because of the greater health risks they face and because of the significant amount of preventable mortality among poor women and their infants. ${ }^{8}$ The Institute of Medicine of the National Academy of Sciences has estimated that each dollar spent on comprehensive maternity care will save $\$ 3.38$.

Unfortunately, despite all that is known about the importance of good maternity care, astonishing numbers of pregnant American women do not receive it. In 1988 more than 1 million of the 3.9 million infants born that year had mothers who did not receive any prenatal care during the first three months of pregnancy. Nearly 250,000 were born to women who received no care until the last three

Table 7

\section{LATINO LOW BIRTHWEICHT* AND INFANT MORTALTY*, 1988}

\begin{tabular}{|c|c|c|c|c|}
\hline & $\begin{array}{l}\text { Low } \\
\text { Birthweight }\end{array}$ & $\begin{array}{c}\text { Infant } \\
\text { Mortality }\end{array}$ & $\begin{array}{l}\text { Neonatal } \\
\text { Mortality }\end{array}$ & $\begin{array}{l}\text { Postneonatal } \\
\text { Mortality }\end{array}$ \\
\hline Latino Total & $6.2 \%$ & 8.1 & 5.0 & 3.0 \\
\hline Mexican & $5.6 \%$ & 7.8 & 4.8 & 3.0 \\
\hline Puerto Rican & $9.4 \%$ & 7.7 & 4.6 & 3.0 \\
\hline Cuban & $5.9 \%$ & - & - & - \\
\hline \multicolumn{5}{|l|}{ Central and } \\
\hline South American & $5.6 \%$ & $\mathrm{n} / \mathrm{a}$ & $\mathrm{n} / \mathrm{a}$ & $\mathrm{n} / \mathrm{a}$ \\
\hline Other Latino"* & $6.8 \%$ & 8.8 & 5.8 & 3.1 \\
\hline \multicolumn{5}{|l|}{ Non-Latino } \\
\hline White & $5.6 \%$ & 8.3 & 5.1 & 3.2 \\
\hline Black & $13.1 \%$ & 17.1 & 10.8 & 6.3 \\
\hline All Origins & $7.0 \%$ & 10.0 & 6.3 & 3.7 \\
\hline \multicolumn{5}{|c|}{$\begin{array}{l}\text { Low-birthweight rates are for } 30 \text { reporting states and the District of } \mathrm{Co} \text { - } \\
\text { lumbia. See Technical Notes for a listing. }\end{array}$} \\
\hline \multicolumn{5}{|c|}{$\begin{array}{l}\text { Mortality rates are for } 23 \text { reporting states and the District of Columbia. } \\
\text { See Technical Notes for a listing. }\end{array}$} \\
\hline \multicolumn{5}{|c|}{ - Deaths per 1,000 live births. } \\
\hline \multicolumn{5}{|c|}{$\begin{array}{l}\text { "Mortality rates for "Other Latino" include Central and South Ameri- } \\
\text { cans. }\end{array}$} \\
\hline \multicolumn{5}{|c|}{$\begin{array}{l}\text { SOURCE: National Center for Health Statistics. Calculations by the } \\
\text { Children's Defense Fund. }\end{array}$} \\
\hline
\end{tabular}

months of pregnancy or who received no care at all. Mothers whose care was the least adequate were the very ones who needed good care the most.

\section{Early prenatal care}

Prenatal care should begin no later than the third month of pregnancy. In 1988, however, only 75.9 percent of all infants were born to women who received early care (Table 9). This proportion represented a slight decline from already inadequate 1987 levels and means that all the gains of the early 1980s were lost. Among white women, 79.4 percent of all live births occurred to mothers who began care early. But among nonwhite women, the proportion of births in which the mother received early

Table 8

PERCENTAGE OF INFANTS BORN AT LOW
BIRTHWEIGHT, SELECTED COUNTRIES,
$1980-1988$

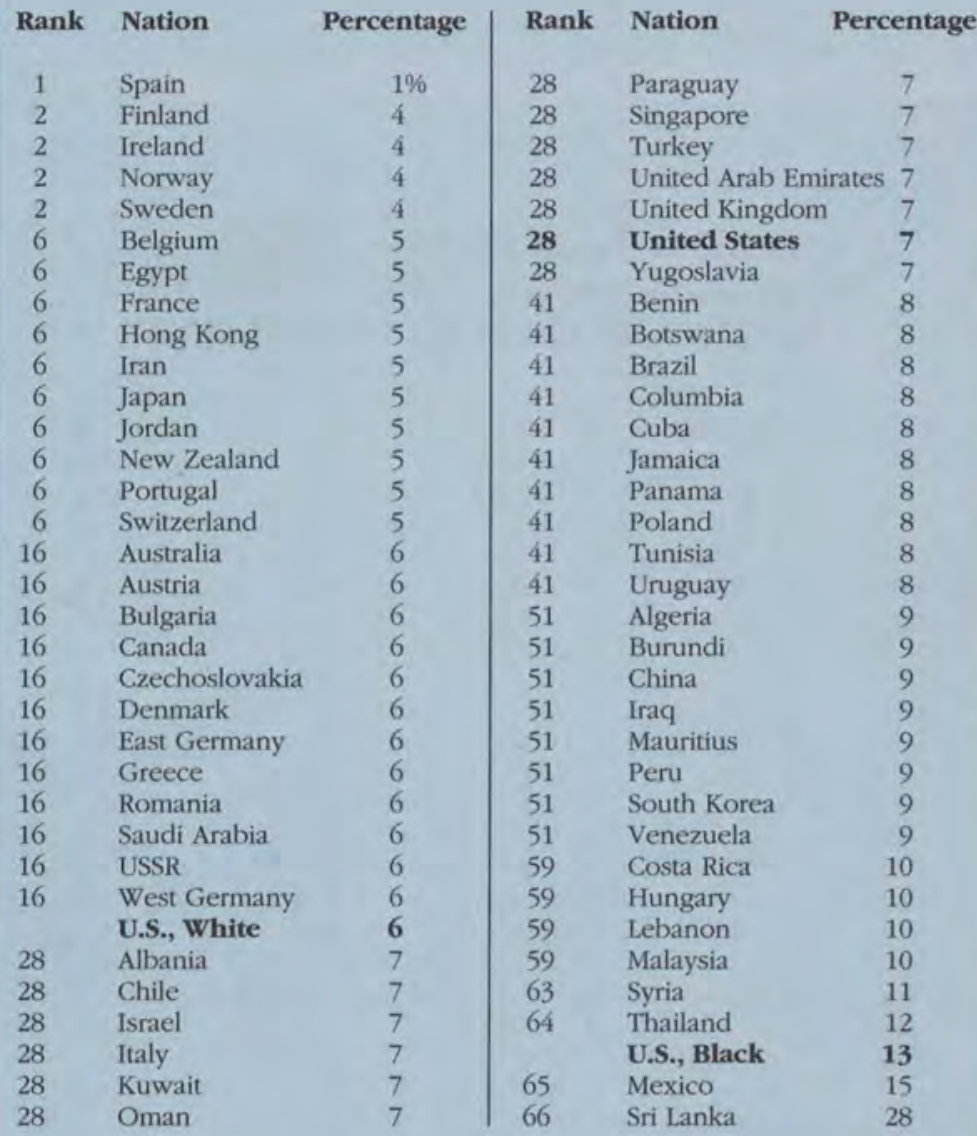

SOURCE: UNICEF, except race specific data for the United States. Race specific data for the U.S. are from the National Center for Health Statistics for 1988. 
care stood at 63.6 percent. For black women the proportion in 1988 was 61.1 percent, a decline from 1987 and the lowest early care proportion since 1978.

Among Latino women, data from the 31 jurisdictions that record the Latino origin of the parents show that 61.3 percent of all births in 1988 were to women who began care early (Table 4 ). This overall number, however, masks extraordinary variations among Latino subpopulations, ranging from 58.3 percent of all Mexican American births to 83.4 percent for Cuban American births - a testament to the extreme poverty of Mexican American women and the relative affluence of Cuban American women.

On the whole, women least likely to begin prenatal care early in pregnancy are young. In 1988 only 53.1 percent of all births to women younger than 20 were to women who began prenatal care during the first three months of pregnancy (Table 1). Among white teenage women, 56.1 percent of all births were to mothers who began care early; for nonwhite and black teenagers, the early care figures were 47.3 percent and 47.1 percent, respectively.

Table 9

PERCENTAGE OF INIFANTS BORN TO MOMEN RECEIYHA EARLY PRENATAL CARE, BY RACE, U.S., I969-1988

\begin{tabular}{lccll} 
& & & \multicolumn{2}{c}{ Nonwhite } \\
1969 & All Races & White & Black & Total \\
1970 & $68.0 \%$ & $72.4 \%$ & $42.7 \%$ & $44.5 \%$ \\
1971 & 67.9 & 72.4 & 44.3 & 46.0 \\
1972 & 68.6 & 73.0 & 44.3 & 48.1 \\
1973 & 69.4 & 73.6 & 49.0 & 50.6 \\
1974 & 70.8 & 74.9 & 51.4 & 52.9 \\
1975 & 72.1 & 75.9 & 53.9 & 55.3 \\
1976 & 72.3 & 75.9 & 55.8 & 57.0 \\
1977 & 73.5 & 76.8 & 57.7 & 58.8 \\
1978 & 74.1 & 77.3 & 59.0 & 60.1 \\
1979 & 74.9 & 78.2 & 60.2 & 61.4 \\
1980 & 75.9 & 79.1 & 61.6 & 62.9 \\
1981 & 76.3 & 79.3 & 62.7 & 63.8 \\
1982 & 76.3 & 79.4 & 62.4 & 63.8 \\
1983 & 76.1 & 79.3 & 61.5 & 63.2 \\
1984 & 76.2 & 79.4 & 61.5 & 63.4 \\
1985 & 76.5 & 79.6 & 62.2 & 64.1 \\
1986 & 76.2 & 79.4 & 61.8 & 63.7 \\
1987 & 75.9 & 79.2 & 61.6 & 63.7 \\
1988 & 76.0 & 79.4 & 61.2 & 63.4 \\
& 75.9 & 79.4 & 61.1 & 63.6
\end{tabular}

- Early prenatal care is defined as starting in the first trimester.

SOURCE: National Center for Health Statistics. Calculations by the Children's Defense Fund.
However, even among older women, significant racial disparities can be seen in who receives early care. For example, in 1988, when 87.7 percent of all white births to women ages 30 to 35 were to mothers who received care early in pregnancy, only 71.8 percent of all black births to women in the same age group were to mothers who began care early in pregnancy. Similarly large disparities can be seen when late and no care rates among infants born to various ages of mothers are compared by race and ethnicity. These figures undoubtedly reflect the greater poverty levels and diminished health insurance status among black women (Figures 2 and 3 , Tables 10 and 11).

In 1989 the White House Task Force on Infant Mortality concluded in a report that was not released by the Bush Administration that the most important factors affecting women's access to early care were a lack of health insurance (particularly among low-income and minority women), poverty and its attendant impact on ability to obtain necessary care, insufficient and inadequate services, and a complex and fragmented health care system. These factors all have an enormous impact on access to care by poor women. Since black and Latino women are twice as likely as white non-Latino women to be poor, they are at far greater risk, regardless of age, for late or no prenatal care.

\section{Late or no care}

Babies born to mothers who receive no care or inadequate care are significantly more likely to die in infancy or be left with lifelong disabilities. While pregnancy is one of the most common conditions affecting women, it is definitely not without risk. Half of all pregnancies involve at least one complication, while 25 percent involve a significant complication..$^{10}$ Late or no care means that health conditions during the pregnancy that can threaten the lives of both mothers and infants go untreated. Late care leaves women without access to basic health services that detect and treat potential problems (such as hypertension and diabetes) in a timely fashion. Women who need extra supports during pregnancy to address such problems as use of drugs, alcohol, or tobacco do not receive it. Women who need nutritional supplementation or access to highly specialized inpatient services before or during delivery may go without it. The end result is a 
Figure 2

\section{PERCENT OF BABIES BORN TO MOTHERS RECEIVING EARIY PRENATAL \\ CARE BY MATERNAL AGE AND RACE, 1988}

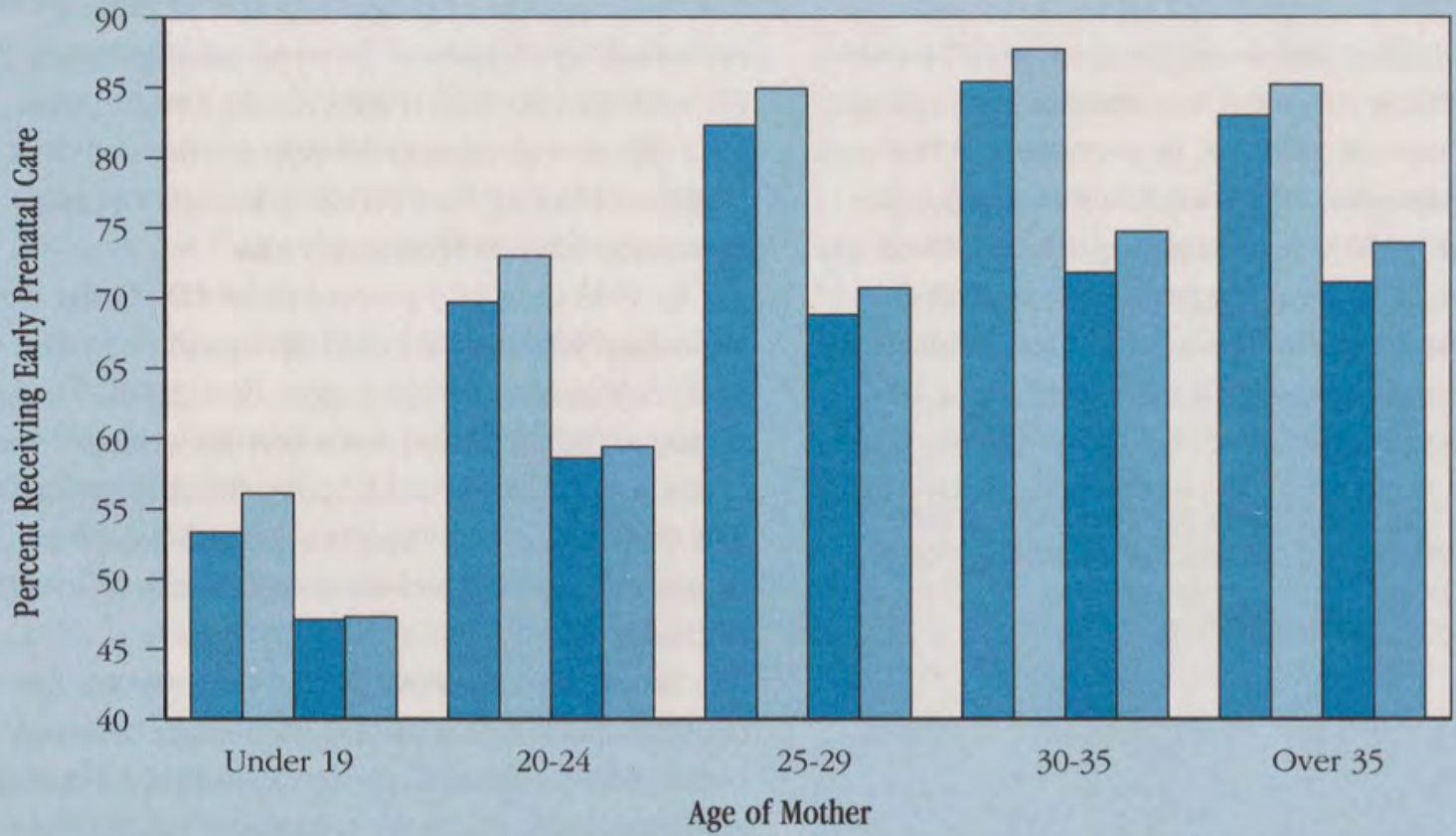

All Races

$\square$ White

Black

Nonwhite

SOURCE: National Center for Health Statistics. Calculations by the Children's Defense Fund

Figure 3

PERCENT OF MOTHERS RECEIVING LATE OR NO PRENATAL CARE BY MATERNAL AGE AND RACE, 1988

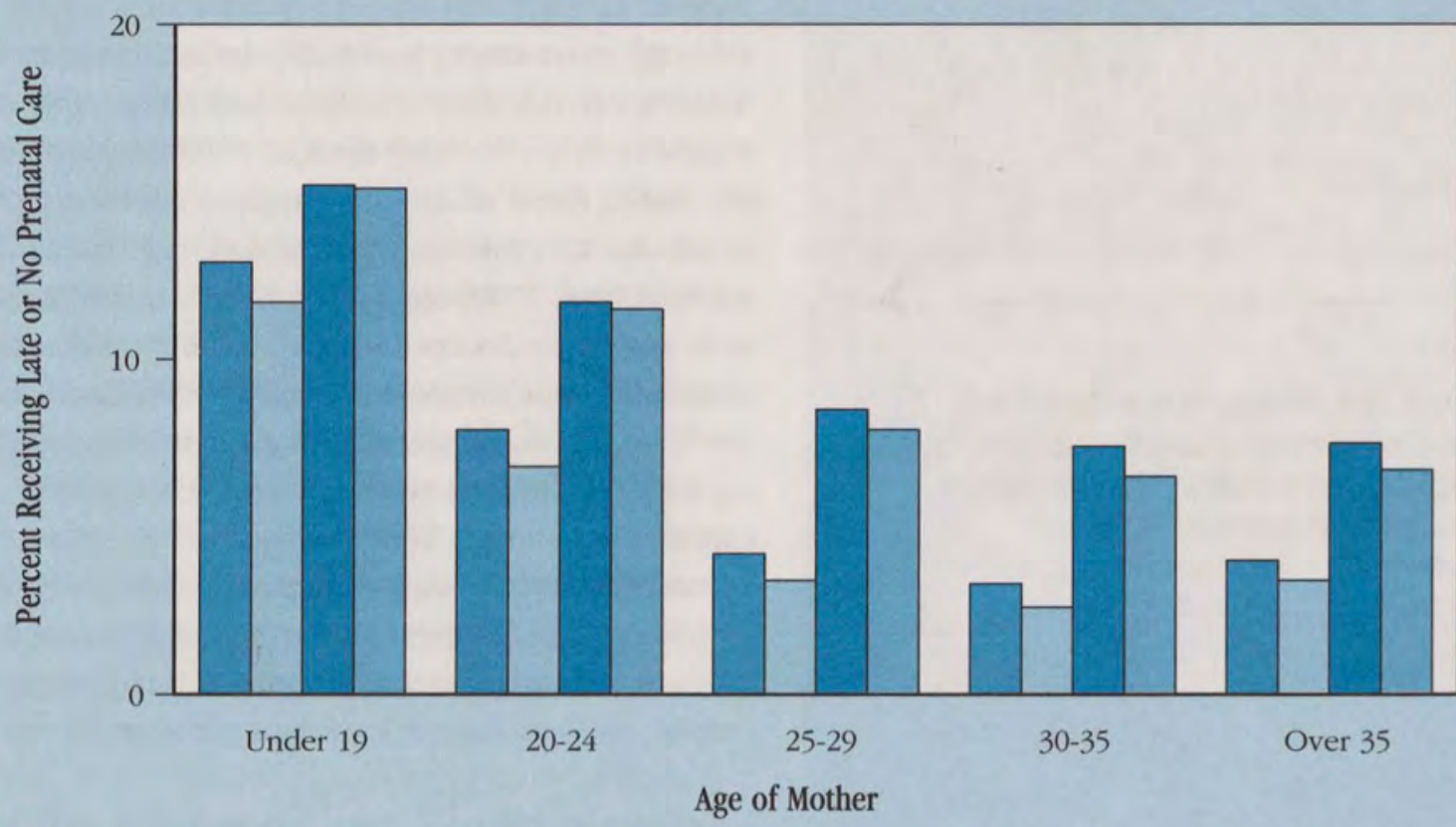

\begin{tabular}{|l}
$\square$ All Races \\
$\square$ White \\
Black \\
Nonwhite
\end{tabular}

SOURCE: National Center for Health Statistics. Calculations by the Children's Defense Fund. 
pregnancy and childbirth with vastly increased risks for both the mother and infant.

In $1988,6.1$ percent of all births were to women who received no care at all or none until the final three months of pregnancy (Table 1), the same as 1987 and higher than in any year since 1974. In every year in the 1980 s the late prenatal care rate got worse or did not improve. In every year in the 1970 s it improved. Among white women, 5.0 percent of all births were to mothers who received late or no care in 1988; among nonwhite and black women the proportions were 10.1 percent and 10.9 percent, respectively. With the exception of 1987 , a higher proportion of black births in 1988 were to women who received late or no prenatal care than in any year since 1975 (Table 12).

\section{Adequacy of prenatal care}

It is not enough that prenatal care begin early in pregnancy: care must be provided continuously

Table 10

\section{PERCENTACE OF INFANTS BORN TO MOTHERS RECEIVING EARLY PRENATAL CARE, BY AGE OF MOTHER AND RACE OF CHIL, 1988}

$\begin{array}{lcccc}\text { Age } & \text { All Races } & \text { White } & \text { Black } & \text { Nonwhite } \\ \text { Under 19 } & 53.1 \% & 56.1 \% & 47.1 \% & 47.3 \% \\ 20-24 & 69.7 & 73.0 & 58.6 & 59.4 \\ 25-29 & 82.3 & 84.9 & 68.8 & 70.7 \\ 30-35 & 85.4 & 87.7 & 71.8 & 74.7 \\ 35 \text { and Older } & 83.0 & 85.2 & 71.1 & 73.9\end{array}$

SOURCE: National Center for Health Statistics. Calculations by the Children's Defense Fund.

Table 11

\section{PERCENTAGE OF INFANTS BORN TO MOTHERS RECEIVING LATE OR NO PRENATAL CARE, BY AGE OF MOTHER AND RACE OF CHILD, 1988}

$\begin{array}{lcccc}\text { Age of Mother } & \text { All Races } & \text { White } & \text { Black } & \text { Nonwhite } \\ \text { Under 19 } & 12.9 \% & 11.7 \% & 15.2 \% & 15.1 \% \\ 20-24 & 7.9 & 6.8 & 11.7 & 11.5 \\ 25-29 & 4.2 & 3.4 & 8.5 & 7.9 \\ 30-35 & 3.3 & 2.6 & 7.4 & 6.5 \\ 35 \text { and Older } & 4.0 & 3.4 & 7.5 & 6.7\end{array}$

SOURCE: National Center for Health Statistics. Calculations by the Children's Defense Fund. throughout pregnancy, as well. Adequate care (as measured by a special index developed in 1973 by Dr. David Kessner, which takes both the timing and frequency of care into account) begins during the first three months of pregnancy and includes a sufficient number of visits to be considered adequate. For example, a woman who carries her pregnancy for a full nine months ( 36 weeks or more) should begin care during the first three months of pregnancy and have at least nine visits.

In 1988 only 68.9 percent of all U.S. births were to women whose care could be considered minimally adequate. That year more than 250,000 infants ( 8 percent of all births) were born to women whose care was considered inadequate. (Inadequate care is care that begins only after the seventh month of pregnancy or that involves no more than four visits or both.)

Racial disparities in adequacy of care are particularly shocking. In 1988, 73.5 percent of white births were to women whose care could be considered minimally adequate. However, only 50.7 percent of all black births were to mothers whose care could be considered adequate (Table 1).

Taken together, these national infant birthweight and prenatal care statistics mean that far too many infants are born too soon and too small, and far too few are born to women whose care is early and adequate. The statistics are particularly depressed for poor and minority women and infants, although even among more affluent, nonminority women, prenatal care utilization and infant birthweight both are far from optimal. To the extent that the United States makes any progress in reducing infant mortality (and provisional national "snapshot" statistics from 1990 suggest that overall infant mortality may have declined enough to be considered significant), this progress is caused by sophisticated, intensive life-saving techniques designed to save dying infants rather than through relatively low-cost care that saves more lives in a far more humane fashion (Table 13). ${ }^{11}$ Any reduction in infant mortality is welcome. But these birthweight and prenatal care numbers suggest that progress is being made only at immense human and financial cost. 


\section{Infant, Child, and Maternal Mortalify}

\section{Infant Mortality}

nfant mortality is one of the most basic indicators of the overall health and welfare of a society. In that context, the U.S. infant mortality statistics are a metaphor for the enormous and widening gulf between the nation's most affluent residents and its most vulnerable.

The U.S. Department of Health and Human Services (HHS) recently reported that provisional oneyear data for 1990 show a 6 percent drop in infant mortality from the period 12 months earlier, from 9.7 to 9.1 infant deaths per 1,000 live births. To the extent that the progress shown in these provisional statistics is maintained in final data (and it is not possible to know whether they are until the data are finalized), the news is welcome, especially after years of very slow progress. HHS officials have credited both improved treatment technologies for extremely premature and low-birthweight newborns and recent reforms in Medicaid and other health programs for the poor for this reduction. ${ }^{12}$

Even if maintained, however, a 1990 infant mortality rate of 9.1 deaths per 1,000 live births exceeds the Surgeon General's modest 1990 goal (set in 1979) of 9 deaths per 1,000 live births. The excess deaths that account for the nation's poor performance are attributable in large measure to the extraordinary death rates from which the nation's black infants suffer. The provisional 1990 statistics do not report the mortality rate for black infants. For these figures it is necessary to analyze infant mortality statistics for 1988 - the latest year for which such data are final.

In 1988 the national infant mortality rate stood at 10.0 deaths per 1,000 live births (Table 1 ). The mortality rate for white infants was 8.5 ; for black and nonwhite infants it was 17.6 and 15.0 , respectively. With the exception of 1987 , the 1988 disparity between the black and white infant mortality rates $(2.07: 1)$ was the widest since infant mortality statistics were first reported by race in 1940 (Table 14).

The 1988 national infant mortality rate was statistically identical to the 1987 rate, according to the National Center for Health Statistics. ${ }^{13}$ Moreover, nei- ther the white nor the black infant mortality rates, considered alone, showed any statistically significant decline from their 1987 levels, according to NCHS, ${ }^{14}$ The year 1988 represented only the second time since 1965 ( 1985 being the only other time) that the national infant mortality rate failed to show any statistically significant decline from one year to the next.

The plight of black infants is positively alarming. At 17.6 deaths per 1,000 live births, the 1988 black infant mortality rate was nearly 50 percent higher than the Surgeon General's 1990 goal of 12.0

Table 12

\section{PERCENTAGE OF INIFANTS BORN TO WOMEN RECEIVING LATE OR NO PRENATAL CARE," BY RACE, U.S., 1969-1988}

$\begin{array}{lcccc}\text { Year } & \text { All Races } & \text { White } & \text { Black } & \text { Nonwhite } \\ 1969 & 8.1 \% & 6.3 \% & 18.2 \% & 17.7 \% \\ 1970 & 7.9 & 6.2 & 16.6 & 16.2 \\ 1971 & 7.2 & 5.8 & 14.6 & 14.1 \\ 1972 & 7.0 & 5.5 & 13.2 & 13.1 \\ 1973 & 6.7 & 5.4 & 12.4 & 12.3 \\ 1974 & 6.2 & 5.0 & 11.4 & 11.2 \\ 1975 & 6.0 & 5.0 & 10.5 & 10.4 \\ 1976 & 5.7 & 4.8 & 9.9 & 9.8 \\ 1977 & 5.6 & 4.7 & 9.6 & 9.5 \\ 1978 & 5.4 & 4.5 & 9.3 & 9.1 \\ 1979 & 5.1 & 4.3 & 8.9 & 8.8 \\ 1980 & 5.1 & 4.3 & 8.8 & 8.8 \\ 1981 & 5.2 & 4.3 & 9.1 & 8.9 \\ 1982 & 5.5 & 4.5 & 9.6 & 9.3 \\ 1983 & 5.6 & 4.6 & 9.7 & 9.4 \\ 1984 & 5.6 & 4.7 & 9.6 & 9.3 \\ 1985 & 5.7 & 4.7 & 10.0 & 9.5 \\ 1986 & 6.0 & 5.0 & 10.6 & 9.9 \\ 1987 & 6.1 & 5.0 & 11.1 & 10.3 \\ 1988 & 6.1 & 5.0 & 10.9 & 10.1\end{array}$

- Late care is defined as starting in the third trimester.

SOURCE: National Center for Health Statistics. Calculations by the Children's Defense Fund.

Table 13

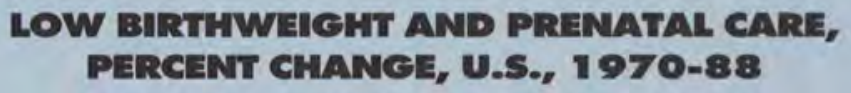

\begin{tabular}{|c|c|c|c|c|c|}
\hline & & & & \multicolumn{2}{|c|}{ Average Annual Percent Change } \\
\hline & 1970 & 1980 & 1988 & 1970-1980 & 1980-1988 \\
\hline Early Prenatal Care & $67.9 \%$ & $76.3 \%$ & $75.9 \%$ & $1.2 \%$ & $-0.1 \%$ \\
\hline Late or No Prenatal Care & 7.9 & 5.1 & 6,1 & -3.5 & 2.5 \\
\hline Low Birthweight & 7.9 & 6.8 & 6.9 & -1.4 & 0.2 \\
\hline
\end{tabular}


Table 14

INFANT MORTALTY RATES, * BY RACE, U.S., 1940-1988

\begin{tabular}{|c|c|c|c|c|c|}
\hline \multirow[b]{2}{*}{ Year } & \multirow[b]{2}{*}{ All Races } & \multirow[b]{2}{*}{ White } & \multicolumn{2}{|c|}{ Nonwhite } & \multirow{2}{*}{$\begin{array}{c}\text { Black to } \\
\text { White }\end{array}$} \\
\hline & & & Black & Total & \\
\hline 1940 & 47.0 & 43.2 & 72.9 & 73.8 & 1.69 \\
\hline 1941 & 45.3 & 41.2 & 74.1 & 74.8 & 1.80 \\
\hline 1942 & 40.4 & 37.3 & 64.2 & 64.6 & 1.72 \\
\hline 1943 & 40.4 & 37.5 & 61.5 & 62.5 & 1.64 \\
\hline 1944 & 39.8 & 36.9 & 59.3 & 60.3 & 1.61 \\
\hline 1945 & 38.3 & 35.6 & 56.2 & 57.0 & 1.58 \\
\hline 1946 & 33.8 & 31.8 & 48.8 & 49.5 & 1.53 \\
\hline 1947 & 32.2 & 30.1 & 47.7 & 48.5 & 1.58 \\
\hline 1948 & 32.0 & 29.9 & 45.7 & 46.5 & 1.58 \\
\hline 1949 & 31.3 & 28.9 & 46.8 & 47.3 & 1.62 \\
\hline 1950 & 29.2 & 26.8 & 43.9 & 44.5 & 1.64 \\
\hline 1951 & 28.4 & 25.8 & 44.3 & 44.8 & 1.72 \\
\hline 1952 & 28.4 & 25.5 & 46.9 & 47.0 & 1.84 \\
\hline 1953 & 27.8 & 25.0 & 44.5 & 44.7 & 1.78 \\
\hline 1954 & 26.6 & 23.9 & 42.9 & 42.9 & 1.79 \\
\hline 1955 & 26.4 & 23.6 & 43.1 & 42.8 & 1.83 \\
\hline 1956 & 26.0 & 23.2 & 42.4 & 42.1 & 1.83 \\
\hline 1957 & 26.3 & 23.3 & 44.2 & 43.7 & 1.90 \\
\hline 1958 & 27.1 & 23.8 & 46.3 & 45.7 & 1.95 \\
\hline 1959 & 26.4 & 23.2 & 44.8 & 44.0 & 1.93 \\
\hline 1960 & 26.0 & 22.9 & 44.3 & 43.2 & 1.93 \\
\hline 1961 & 25.3 & 22.4 & 41.8 & 40.7 & 1.87 \\
\hline 1962 & 25.3 & 22.3 & 42.6 & 41.4 & 1.91 \\
\hline 1963 & 25.2 & 22.2 & 42.8 & 41.5 & 1.93 \\
\hline 1964 & 24.8 & 21.6 & 42.3 & 41.1 & 1.96 \\
\hline 1965 & 24.7 & 21.5 & 41.7 & 40.3 & 1.94 \\
\hline 1966 & 23.7 & 20.6 & 40.2 & 38.8 & 1.95 \\
\hline 1967 & 22.4 & 19.7 & 37.5 & 35.9 & 1.90 \\
\hline 1968 & 21.8 & 19.2 & 36.2 & 34.5 & 1.89 \\
\hline 1969 & 20.9 & 18.4 & 34.8 & 32.9 & 1.89 \\
\hline 1970 & 20.0 & 17.8 & 32.6 & 30.9 & 1.83 \\
\hline 1971 & 19.1 & 17.1 & 30.3 & 28.5 & 1.77 \\
\hline 1972 & 18.5 & 16.4 & 29.6 & 27.7 & 1.80 \\
\hline 1973 & 17.7 & 15.8 & 28.1 & 26.2 & 1.78 \\
\hline 1974 & 16.7 & 14.8 & 26.8 & 24.9 & 1.81 \\
\hline 1975 & 16.1 & 14.2 & 26.2 & 24.2 & 1.85 \\
\hline 1976 & 15.2 & 13.3 & 25.5 & 23.5 & 1.92 \\
\hline 1977 & 14.1 & 12.3 & 23.6 & 21.7 & 1.92 \\
\hline 1978 & 13.8 & 12.0 & 23.1 & 21.1 & 1.93 \\
\hline 1979 & 13.1 & 11.4 & 21.8 & 19.8 & 1.91 \\
\hline 1980 & 12.6 & 11.0 & 21.4 & 19.1 & 1.95 \\
\hline 1981 & 11.9 & 10.5 & 20.0 & 17.8 & 1.90 \\
\hline 1982 & 11.5 & 10.1 & 19.6 & 17.3 & 1.94 \\
\hline 1983 & 11.2 & 9.7 & 19.2 & 16.8 & 1.98 \\
\hline 1984 & 10.8 & 9.4 & 18.4 & 16.1 & 1.96 \\
\hline 1985 & 10.6 & 9.3 & 18.2 & 15.8 & 1.96 \\
\hline 1986 & 10.4 & 8.9 & 18.0 & 15.7 & 2.02 \\
\hline 1987 & 10.1 & 8.6 & 17.9 & 15.4 & 2.08 \\
\hline 1988 & 10.0 & 8.5 & 17.6 & 15.0 & 2.07 \\
\hline
\end{tabular}

- Deaths per 1,000 live births.

SOURCE: National Center for Health Statistics. Calculations by the Children's Defense Fund.
Table 15

EXCESS BLACK INFANT DEATHS,* $1940-1988$

$\begin{array}{lcc}\text { Black } & \begin{array}{c}\text { Actual } \\ \text { Black }\end{array} & \begin{array}{c}\text { Excess } \\ \text { Black } \\ \text { Deaths } \\ \text { Deaths }\end{array} \\ 278,869 & 20,342 & 8,285 \\ 294,554 & 21,834 & 9,694 \\ 307,777 & 19,756 & 8,286 \\ 324,865 & 19,967 & 7,794 \\ 324,183 & 19,234 & 7,268 \\ 324,264 & 18,228 & 6,682 \\ 358,114 & 17,480 & 6,110 \\ 406,957 & 19,420 & 7,173 \\ 434,174 & 19,836 & 6,864 \\ 453,235 & 21,213 & 8,131 \\ 466,718 & 20,492 & 7,997 \\ 489,282 & 21,665 & 9,017 \\ 497,880 & 23,360 & 10,660 \\ 517,576 & 23,009 & 10,051 \\ 544,288 & 23,323 & 10,331 \\ 558,251 & 24,046 & 10,861 \\ 584,572 & 24,785 & 11,231 \\ 596,050 & 26,360 & 12,467 \\ 594,500 & 27,528 & 13,393 \\ 605,962 & 27,164 & 13,100 \\ 602,264 & 26,691 & 12,895 \\ 611,072 & 25,573 & 11,864 \\ 584,610 & 24,911 & 11,853 \\ 580,658 & 24,824 & 11,954 \\ 607,556 & 25,721 & 12,606 \\ 581,126 & 24,230 & 11,729 \\ 558,244 & 22,427 & 10,911 \\ 543,976 & 20,372 & 9,663 \\ 531,152 & 19,219 & 9,023 \\ 543,132 & 18,882 & 8,884 \\ 572,362 & 18,687 & 8,526 \\ 564,960 & 17,131 & 7,487 \\ 531,329 & 15,738 & 7,042 \\ 512,597 & 14,411 & 6,325 \\ 507,162 & 13,584 & 6,053 \\ 511,581 & 13,409 & 6,158 \\ 514,479 & 13,142 & 6,297 \\ 544,221 & 12,863 & 6,149 \\ 551,540 & 12,747 & 6,121 \\ 577,855 & 12,586 & 5,985 \\ 589,616 & 12,603 & 6,118 \\ 587,797 & 11,757 & 5,598 \\ 592,641 & 11,642 & 5,668 \\ 586,027 & 11,242 & 5,531 \\ 592,745 & 10,881 & 5,283 \\ 608,193 & 11,063 & 5,398 \\ 621,221 & 11,204 & 5,649 \\ 641,567 & 11,461 & 5,928 \\ 671,976 & 11,840 & 6,121 \\ & & \\ \mathbf{8 5}, 730 & & \mathbf{4 1 4} \\ & & \end{array}$

- "Excess black infant deaths" is defined as the number of black infants who would not have died if the black infant mortality rate was as low as the rate among whites.

SOURCE: National Center for Health Statistics. Calculations by the Children's Defense Fund. 
deaths per 1,000 live births for all racial and ethnic minority infants. The 1988 black infant mortality rate was virtually identical to the white rate nearly a generation earlier. Grossly elevated black infant mortality rates over the past half century have caused an excess of nearly 415,000 infant deaths that would not have occurred had the black rate equalled the rate for white infants (Table 15).

\section{Neonatal mortality}

Neonatal mortality (deaths of infants younger than 28 days of age) declined from 6.5 to 6.3 deaths per 1,000 live births in 1988 . The black neonatal mortality rate of 11.5 was 2.13 times higher than the white rate of 5.4 (Table 16). The 1988 disparity between black and white newborn death rates stood at its widest point since 1950 .

Neonatal mortality is related closely to low birthweight. Infants born at low birthweight are 20 times more likely to die during infancy and 40 times more likely to die in the neonatal period. The enormous disparities between black and white lowbirthweight rates (Table 5), therefore, account for much of the disparity in black and white infant deaths.

\section{Postneonatal mortality}

Postneonatal mortality (deaths among infants ages 28 days to one year old) is by and large a reflection of the living conditions that await children after they are born. Most postneonatal mortality can be traced to deaths among infants born at normal weight. The

\section{Table 16

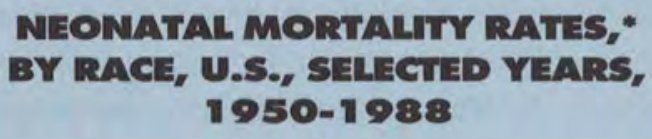

$\begin{array}{lcc}\text { Year } & \text { All Races } & \text { White } \\ 1950 & 20.5 & 19.4\end{array}$

1955

1960

1961

1962

1963

1964

1965

1966

1967

1968

1969

1970

1971

1972

1973

1974

1975

1976

1977

1978

1979

1980

1981

1982

1983

1984

1985

1986

1987

1988

\begin{tabular}{cr}
\multicolumn{2}{c}{ Nonwhite } \\
Black & Total \\
27.8 & 27.5
\end{tabular}

$\begin{array}{ll}19.1 & 17.7\end{array}$

$18.7 \quad 17.2$

$18.4 \quad 16.9$

$18.3 \quad 16.9$

$18.2 \quad 16.7$

$17.9 \quad 16.2$

$17.7 \quad 16.1$

$17.2 \quad 15.6$

$16.5 \quad 15.0$

$16.1 \quad 14.7$

$15.6 \quad 14.2$

$15.1 \quad 13.8$

$14.2 \quad 13.0$

$13.6 \quad 12.4$

$13.0 \quad 11.8$

$12.3 \quad 11.1$

$11.6 \quad 10.4$

$10.9 \quad 9.7$

$\begin{array}{ll}9.9 & 8.7\end{array}$

$9.5 \quad 8.4$

$8.9 \quad 7.9$

$8.5 \quad 7.5$

$8.0 \quad 7.1$

7.7

7.3

7.0

7.0

6.7

6.5

6.3
Ratio of

Black to

White

1.43

1.57

1.62

1.55

1.60

1.62

1.69

1.65

1.66

1.67

1.65

1.68

1.65

1.62

1.67

1.64

1.68

1.76

1.85

1.85

1.85

1.81

1.88

1.89

1.93

1.94

1.90

1.98

2.02

2.13

2.13

- Deaths within 28 days after birth per 1,000 live births.

SOURCE; National Center for Health Statistics. Calculations by the Children's Defense Fund.
Table 17

\section{POSTNEONATAL MORTALITY RATES,* BY RACE, U.S., SELECTED YEARS, 1950-1988}

\begin{tabular}{lcrrrc} 
Year & All Races & White & \multicolumn{2}{c}{$\begin{array}{c}\text { Nonwhite } \\
\text { Black }\end{array}$} & $\begin{array}{c}\text { Ratio of } \\
\text { Black to }\end{array}$ \\
1950 & 8.7 & 7.4 & 16.1 & 17.0 & $\begin{array}{c}\text { White } \\
1955\end{array}$ \\
19.3 & 5.9 & 15.3 & 15.6 & 2.59 \\
1960 & 7.3 & 5.7 & 16.5 & 16.3 & 2.89 \\
1961 & 6.9 & 5.5 & 14.7 & 14.5 & 2.67 \\
1962 & 7.0 & 5.4 & 15.5 & 15.3 & 2.87 \\
1963 & 7.0 & 5.5 & 15.8 & 15.4 & 2.87 \\
1964 & 6.9 & 5.4 & 14.8 & 14.6 & 2.74 \\
1965 & 7.0 & 5.4 & 15.2 & 14.9 & 2.81 \\
1966 & 6.5 & 5.0 & 14.3 & 14.0 & 2.86 \\
1967 & 5.9 & 4.7 & 12.5 & 12.1 & 2.66 \\
1968 & 5.7 & 4.5 & 11.9 & 11.5 & 2.64 \\
1969 & 5.3 & 4.2 & 10.8 & 10.4 & 2.57 \\
1970 & 4.9 & 4.0 & 9.9 & 9.5 & 2.48 \\
1971 & 4.9 & 4.1 & 9.3 & 8.9 & 2.27 \\
1972 & 4.9 & 4.0 & 8.9 & 8.5 & 2.23 \\
1973 & 4.7 & 4.0 & 8.8 & 8.3 & 2.20 \\
1974 & 4.4 & 3.7 & 8.1 & 7.7 & 2.19 \\
1975 & 4.5 & 3.8 & 7.9 & 7.4 & 2.08 \\
1976 & 4.3 & 3.6 & 7.6 & 7.2 & 2.11 \\
1977 & 4.2 & 3.6 & 7.6 & 7.0 & 2.11 \\
1978 & 4.3 & 3.6 & 7.6 & 7.1 & 2.11 \\
1979 & 4.2 & 3.5 & 7.5 & 6.9 & 2.14 \\
1980 & 4.1 & 3.5 & 7.3 & 6.6 & 2.09 \\
1981 & 3.9 & 3.4 & 6.6 & 6.0 & 1.94 \\
1982 & 3.8 & 3.3 & 6.5 & 6.0 & 1.97 \\
1983 & 3.9 & 3.3 & 6.8 & 6.0 & 2.06 \\
1984 & 3.8 & 3.2 & 6.6 & 5.9 & 2.06 \\
1985 & 3.7 & 3.2 & 6.1 & 5.5 & 1.91 \\
1986 & 3.6 & 3.1 & 6.3 & 5.6 & 2.03 \\
1987 & 3.6 & 3.1 & 6.1 & 5.4 & 1.97 \\
1988 & 3.6 & 3.1 & 6.2 & 5.4 & 2.00
\end{tabular}

- Deaths between 28 days and one year after birth per 1,000 live births. SOURCE: National Center for Health Statistics. Calcuations by the Children's Defense Fund. 
1988 postneonatal mortality rate stood at 3.6 per 1,000 live births. The year 1988 represented the second consecutive year in which postneonatal mortality failed to decline at all (Table 17). Not since the 1970-1972 period has the national postneonatal mortality rate experienced such a period of stagnation.

While the white postneonatal mortality rate remained at 3.1 deaths per 1,000 live births, the black rate actually increased slightly, from 6.1 to 6.2 deaths per 1,000 live births.

\section{Deaths among Latino infants}

Twenty-three states and the District of Columbia report infant deaths by Latino origin. For these 24 jurisdictions, the 1988 Latino infant mortality rate stood at 8.1 deaths per 1,000 , lower than the white non-Latino infant mortality rate (Table 7). While the 24 jurisdictions represent about 80 percent of the U.S. Latino population, the National Center for Health Statistics also cautions that Latino infant mortality rates may be underestimated significantly because of problems in classification of deaths. ${ }^{15}$ Additional deaths among Latino infants born in the United States in states that border Mexico may go unreported because the infants die in Mexico.

\section{Causes of infant death}

While aggregate infant mortality numbers tell much of the story, the statistics on death by cause underscore the gulf between black and white infants. There is virtually no variation in black and white death rates resulting from nonpreventable causes, such as untreatable congenital anomalies (Table 18). However, the disparities are profound among causes of death that are either wholly or in great part preventable. For example, in 1988 black infants were 3.88 times more likely to die from disorders relating to short gestation and low birthweight, 3.20 times more likely to die from homicide, 2.39 times more likely to die from septicemia, 2.09 times more likely to die from meningitis, and 2.64 times more likely to die from maternal complications of pregnancy.

\section{Maternal Mortality}

In the United States, maternal mortality, like infant mortality, continues to be a stark and basic reminder of the enormous variation in living standards among Americans. In 1988 the national maternal mortality rate leaped upward by more than 27 percent. The nationwide rise in maternal mortality was only the

Table 18

\section{INFANT MORTALTY RATES* FOR THE LEADING CAUSES OF INFANT DEATH, BY RACE, U.S., 1988}

All Causes
1 Congenital anomalies
2 Sudden infant death syndrome
3 Disorders relating to short
gestation and low birthweight
4 Respiratory distress syndrome
5 Maternal complications of pregnancy
6 Accidents and adverse effects
7 Complications of placenta,
8 Perinatal infections
9 Hypoxia and birth asphyxia
10 Pneumonia and influenza
11 Neonatal hemorrhage
12 Homicide
13 Septicemia
14 Birth trauma
15 Meningitis

All Race

995.3
208.2
140.1

83.6
81.4
36.1
23.9

23.2
22.5
19.9
16.4
8.3
8.1
6.3
5.5
5.2

White

851.1

211.5

123.8

56.7

70.5

28.7

20.9

20.2

18.8

17.3

12.7

6.5

5.9

5.1

4.9

4.4
Black

$1,762.0$

209.8

226.2

219.9

142.4

75.7

41.8

39.9

41.5

34.5

33.3

17.3

18.9

12.2

8.8

9.2

Nonwhite
$1,504.0$
196.8
197.5
178.6
119.7
62.1
34.5

33.8
35.2
29.0
29.4
14.6
15.6
10.4
7.9
8.1

Ratio of

Black

to White

2.07

0.99

1.83

3.88

2.02

2.64

2.00

1.98

2.21

1.99

2.62

2.66

3.20

2.39

1.80

2.09

- Deaths per 100,000 live births.

SOURCE: National Center for Health Statistics. Calculations by the Children's Defense Fund. 
fourth time since 1940, when national data first became available, that maternal mortality increased (two of those times were in the 1980s), and was the largest one-year increase in that entire period (Table 19).

The ratio of nonwhite to white maternal deaths in 1988 stood at 2.9:1. As with infant mortality, the greatest disparities by race in maternal mortality arose from causes considered largely preventable, including ectopic pregnancies and direct obstetric causes.

\section{Infernational Findings: Infant and Child Mortality}

The United States fares poorly when its infant and child mortality rates are compared with those of other nations. In 1989, according to statistics from the United Nations International Children's and Education Fund (UNICEF), the overall U.S. infant mortality rate placed nineteenth among all nations, worse than East Germany, Ireland, and Spain (Table 20). And the nation's mortality rate for children younger than five ranked nineteenth, worldwide, worse than Ireland and Spain. In 1989 an American child was twice as likely as one from Japan to die before reaching his or her fifth birthday (Table 21).

\section{Preventable Disease and Childhood Immunizations}

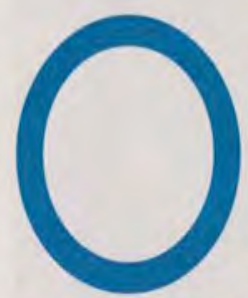

$\mathrm{f}$ all the adverse trends in children's health over the past decade, perhaps none has been more disheartening than the collapse of the nation's childhood vaccine system and the precipitous (and inevitable) rise in the incidence of preventable childhood disease. By 1990 the nation was facing epidemics of such killers and disablers of children as measles, which less than a decade before had been nearly eliminated. According to Dr. D.A. Henderson, one of the world's leading authorities on vaccine programs, the U.S. record for vaccinating children younger than two probably is now worse than that of any Western Hemisphere nation other than Bolivia and Haiti.

By the end of 1990 (the year in which there
Table 19

MATERNAL MORTALTY RATES*, BY RACE, U.S., 1940-1988

\begin{tabular}{|c|c|c|c|c|c|}
\hline Year & All Races & White & Black & Nonwhite & $\begin{array}{l}\text { Ratio of } \\
\text { Black } \\
\text { to White }\end{array}$ \\
\hline 1940 & 376.0 & 319.8 & 781.7 & 773.5 & 2.4 \\
\hline 1941 & 316.5 & 266.0 & 690.2 & 678.1 & 2.6 \\
\hline 1942 & 258.7 & 221.8 & 549.1 & 544.0 & 2.5 \\
\hline 1943 & 245.2 & 210.5 & 512.8 & 509.9 & 2.4 \\
\hline 1944 & 227.9 & 189.4 & 513.9 & 506.0 & 2.7 \\
\hline 1945 & 207.2 & 172.1 & 456.7 & 454.8 & 2.7 \\
\hline 1946 & 156.7 & 130.7 & 363.6 & 358.9 & 2.8 \\
\hline 1947 & 134.5 & 108.6 & 336.2 & 334.6 & 3.1 \\
\hline 1948 & 116.6 & 89,4 & 303.6 & 301.1 & 3.4 \\
\hline 1949 & 90.3 & 68.1 & 237.6 & 234.8 & 3.5 \\
\hline 1950 & 83.3 & 61.1 & 223.0 & 221.6 & 3.6 \\
\hline 1951 & 75.0 & 54.9 & 204.2 & 201.3 & 3.7 \\
\hline 1952 & 67.8 & 48.9 & 189.2 & 188.1 & 3.9 \\
\hline 1953 & 61.1 & 44.1 & 168.3 & 166.1 & 3.8 \\
\hline 1954 & 52.4 & 37.2 & 145.9 & 143.8 & 3.9 \\
\hline 1955 & 47.0 & 32.8 & 134.3 & 130.3 & 4.1 \\
\hline 1956 & 40.9 & 28.7 & 114.3 & 110.7 & 4.0 \\
\hline 1957 & 41.0 & 27.5 & 121.6 & 118.3 & 4.4 \\
\hline 1958 & 37.6 & 26.3 & 104.5 & 101.8 & 4.0 \\
\hline 1959 & 37.4 & 25.8 & 105.0 & 102.1 & 4.1 \\
\hline 1960 & 37.1 & 26.0 & 103.6 & 97.9 & 4.0 \\
\hline 1961 & 36.9 & 24.9 & 105.4 & 101.3 & 4.2 \\
\hline 1962 & 35.2 & 23.8 & 99.4 & 95.9 & 4.2 \\
\hline 1963 & 35.8 & 24.0 & 101.1 & 96.9 & 4.2 \\
\hline 1964 & 33.3 & 22.3 & 93.8 & 89.9 & 4.2 \\
\hline 1965 & 31.6 & 21.0 & 88.3 & 83.7 & 4.2 \\
\hline 1966 & 29.1 & 20.2 & 74.2 & 72.4 & 3.7 \\
\hline 1967 & 28.0 & 19.5 & 72.6 & 69.5 & 3.7 \\
\hline 1968 & 24.5 & 16.6 & 65.9 & 63.6 & 4.0 \\
\hline 1969 & 22.2 & 15.5 & 59.5 & 55.7 & 3.8 \\
\hline 1970 & 21.5 & 14.4 & 59.8 & 55.9 & 4.2 \\
\hline 1971 & 18.8 & 13.0 & 48.3 & 45.3 & 3.7 \\
\hline 1972 & 18.8 & 14.3 & 40.7 & 38.5 & 2.8 \\
\hline 1973 & 15.2 & 10.7 & 38.4 & 34.6 & 3.6 \\
\hline 1974 & 14.6 & 10.0 & 38.3 & 35.1 & 3.8 \\
\hline 1975 & 12.8 & 9.1 & 31.3 & 29.0 & 3.4 \\
\hline 1976 & 12.3 & 9.0 & 29.5 & 26.5 & 3.3 \\
\hline 1977 & 11.2 & 7.7 & 29.2 & 26.0 & 3.8 \\
\hline 1978 & 9.6 & 6.4 & 25.0 & 23.0 & 3.9 \\
\hline 1979 & 9.6 & 6.4 & 25.1 & 22.7 & 3.9 \\
\hline 1980 & 9.2 & 6.7 & 21.5 & 19.8 & 3.2 \\
\hline 1981 & 8.5 & 6.3 & 20.4 & 17.3 & 3.2 \\
\hline 1982 & 7.9 & 5.8 & 18.2 & 16.4 & 3.1 \\
\hline 1983 & 8.0 & 5.9 & 18.3 & 16.3 & 3.1 \\
\hline 1984 & 7.8 & 5.4 & 19.7 & 16.9 & 3.6 \\
\hline 1985 & 7.8 & 5.2 & 20.4 & 18.1 & 3.9 \\
\hline 1986 & 7.2 & 4.9 & 18.8 & 16.0 & 3.8 \\
\hline 1987 & 6.6 & 5.1 & 14.2 & 12.0 & 2.8 \\
\hline 1988 & 8.4 & 5.9 & 19.5 & 17.4 & 3.3 \\
\hline
\end{tabular}

- Deaths per 100,000 live births.

SOURCE: National Center for Health Statistics. Calculations by the Children's Defense Fund. 
were to be no more than 500 cases of measles nationally under goals set in 1979 by the Surgeon General of the United States) more than 25,000 cases of measles were reported (Figure 4). More children died from measles in 1990 than in any year since 1971 . Measles is a particularly sensitive indicator of the nation's eroding childhood immunization system because it is so contagious. Other diseases such as mumps and pertussis are showing similar surges (Table 22 ).

These increases in diseases could have been predicted, since data from the Centers for Disease Control (CDC) indicate a significant decline in childhood immunization rates among children younger

Table 20

\section{INFANT MORTALTY RATE, SELECTED COUNTRIES, 1989}

\begin{tabular}{|c|c|c|}
\hline Rank & Nation & Rate* \\
\hline 1 & Japan & \\
\hline 2 & Finland & \\
\hline 2 & Sweden & \\
\hline 4 & Canada & \\
\hline 4 & Hong Kong & \\
\hline 4 & Netherlands & \\
\hline 4 & Switzerland & \\
\hline 8 & Australia & \\
\hline 8 & Austria & \\
\hline 8 & Denmark & \\
\hline 8 & East Germany & 8 \\
\hline 8 & France & \\
\hline 8 & Norway & \\
\hline 8 & Singapore & \\
\hline 8 & United Kingdom & \\
\hline 8 & West Germany & \\
\hline 17 & Ireland & \\
\hline \multirow[t]{2}{*}{17} & Spain & \\
\hline & U.S., White & \\
\hline 19 & Belgium & 10 \\
\hline 19 & Israel & 10 \\
\hline 19 & Italy & 10 \\
\hline 19 & New Zealand & 10 \\
\hline 19 & United States & 10 \\
\hline 24 & Cuba & 11 \\
\hline 24 & Czechoslovakia & 11 \\
\hline 24 & Greece & 11 \\
\hline 27 & Portugal & 13 \\
\hline 28 & Bulgaria & 14 \\
\hline 29 & Trinidad and Tobago & 15 \\
\hline 30 & Hungary & 16 \\
\hline 30 & Jamaica & 16 \\
\hline 30 & Poland & 16 \\
\hline 33 & Kuwait & 17 \\
\hline \multirow[t]{2}{*}{34} & Costa Rica & 18 \\
\hline & U.S., Black & 18 \\
\hline
\end{tabular}

- Infant deaths per 1,000 live births.

SOURCE: UNICEF, except race specific data for the United States. Race specific data for the U.S, are from the National Center for Health Statistics for 1988. than two during the first half of the decade (data for the latter half of the decade are unavailable because the Reagan Administration ceased collection of national data on children's immunization rates in 1985, and a new planned data collection system has not yet begun) (Table 23). In 1990 the U.S. Public Health service estimated that only 70 to 80 percent of children younger than two are fully vaccinated against preventable disease, and special studies in large cities conducted by the CDC reveal immunization statistics for infants and toddlers at levels of 50 percent or less.

The deterioration of the U.S. child vaccination system has multiple causes: skyrocketing vaccine

Table 21

\section{MORTALTY RATES FOR CHILDREN YOUNGER THAN FIVE, SELECTED COUNTRIES, 1989}

\begin{tabular}{|c|c|c|}
\hline Rank & Nation & Rate \\
\hline 1 & Japan & 6 \\
\hline 2 & Finland & 7 \\
\hline 2 & Sweden & 7 \\
\hline 4 & Hong Kong & 8 \\
\hline 4 & Netherlands & 8 \\
\hline 6 & Australia & 9 \\
\hline 6 & Canada & 9 \\
\hline 6 & East Germany & 9 \\
\hline 6 & France & 9 \\
\hline 6 & Switzerland & 9 \\
\hline 11 & Austria & 10 \\
\hline 11 & Denmark & 10 \\
\hline 11 & Norway & 10 \\
\hline 11 & Spain & 10 \\
\hline 11 & United Kingdom & 10 \\
\hline 11 & West Germany & 10 \\
\hline 17 & Ireland & 11 \\
\hline 17 & Italy & 11 \\
\hline 19 & Belgium & 12 \\
\hline 19 & Greece & 12 \\
\hline 19 & Israel & 12 \\
\hline 19 & New Zealand & 12 \\
\hline 19 & Singapore & 12 \\
\hline 19 & United States & 12 \\
\hline 25 & Czechoslovakia & 13 \\
\hline 26 & Cuba & 14 \\
\hline 27 & Portugal & 16 \\
\hline 28 & Bulgaria & 17 \\
\hline 28 & Hungary & 17 \\
\hline 30 & Poland & 18 \\
\hline 30 & Trinidad and Tobago & 18 \\
\hline 32 & Kuwait & 20 \\
\hline 33 & Jamaica & 21 \\
\hline 34 & Costa Rica & 22 \\
\hline
\end{tabular}

- Deaths per 1,000 live births.

SOURCE: UNICEF. 
prices - with increases of as much as 4,000 percent between 1981 and 1990 (Table 24); increasing and widespread failure of private physicians to vaccinate their young patients because of the high price of buying vaccines and (to a lesser extent) concerns about liability; and a major shortage of vaccine supplies, staff, and resources in local public health clinics and federally funded Community and Migrant Health Centers, which together must absorb the growing numbers of children in need of public vaccine programs because of the withdrawal of private physicians, and because of growing poverty and lack of health insurance. The National Vaccine Advisory Committee, a congressionally established committee that advises the Secretary of Health and Human Services on national vaccine issues, reported in January 1991 that systemic breakdowns, not parental neglect, lay at the heart of declining childhood immunization rates and the measles epidemic. ${ }^{16} \mathrm{~A}$ recent study conducted by CDF found that more than 70 percent of Community and Migrant Health Centers either were experiencing or recently had experi- enced shortages of childhood vaccines, only half could afford to replace needed supplies, and nearly two-thirds were limited in their vaccination efforts by staff or supply shortages. ${ }^{17}$

The nation's eroding childhood vaccine system ironically has coincided with major efforts by socalled "underdeveloped" nations to immunize all children. Responding to a UNICEF-set goal of universal childhood immunization, many less developed nations have undertaken extraordinary public health mobilizations that have improved immunization levels dramatically. In a great historical turnaround, the U.S. immunization rates now lag behind many poorer nations. Among the 16 countries with higher immunization rates than that of the United States in 1988-1989 (as measured by one-year-olds fully immunized against polio) were Bulgaria, Hungary, Greece, Brazil, China, Mexico, and Romania. Among the 55 nations with infant polio immunization rates higher than those for nonwhite U.S. infants were Iran, Malawi, Botswana, and Mongolia (Table 25).

Figure 4

\section{MEASLES CASES, BY STATE, U.S., $1990^{*}$}

United States Total: 25,421

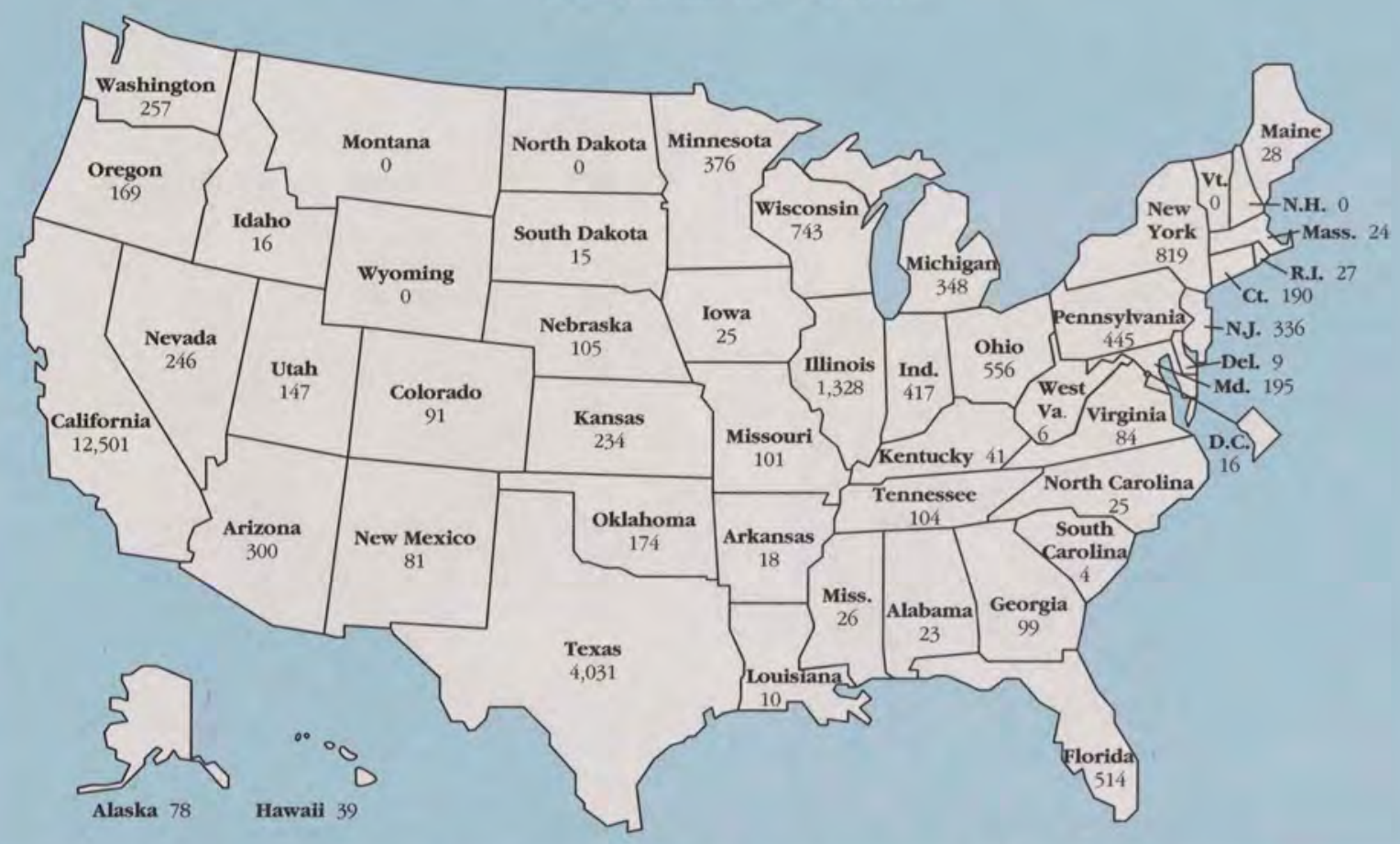

- Cases reported through December 29, 1990. Does not include 1,099 imported cases. State numbers do not include out-of-state cases. SOURCE: Centers for Disease Control. 
Table 22

\section{CASES OF SELECTED PREVENTABLE CHILDHOOD DISEASES, 1980 AND 1990}

$\begin{array}{lcrrr}\begin{array}{l}\text { Surgeon General's } \\ \text { Goal for 1990 } \\ \text { (No. of Cases) }\end{array} & \begin{array}{c}\text { Number } \\ \text { of Cases } \\ \text { in 1980 }\end{array} & \begin{array}{c}\text { Lowest Number } \\ \text { of Cases } \\ \text { (and year) }\end{array} & \begin{array}{r}\text { Number } \\ \text { of Cases } \\ \text { in 1990* }\end{array} \\ \begin{array}{l}\text { Disease } \\ \text { Measles }\end{array} & 500 & 13,506 & 1,497(1983) & 25,421 \\ \text { Rubella } & 1,000 & 3,904 & 225(1988) & 1,093 \\ \text { Mumps } & 1,000 & 8,576 & 2,982(1985) & 5,075 \\ \text { Pertussis } & 1,000 & 1,730 & 1,248(1981) & 4,188\end{array}$

- Cases reported through December 29, 1990.

SOURCE: Centers for Disease Control.

\section{Access to Health Care}

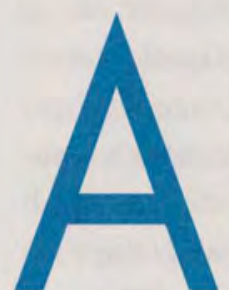

ccess to comprehensive health care is an investment that industrialized nations, with the exception of the United States and South Africa, have made for all pregnant women and children.

Access to adequate health care is strongly related to two distinct issues: having health insurance and having an accessible, affordable, and good quality source of health care. The United States fares badly on both measures. In the United States more than 9 million women of childbearing age are completely uninsured or else lack coverage for maternity

Table 23

\section{PERCENTAGE OF INFANTS AND TODDLERS WHO WERE FULLY IMMUNIZED*, BY AGE AND RACE, U.S. ${ }^{+}, 1980$ AND 1985}

\begin{tabular}{|c|c|c|c|c|c|c|}
\hline Infants & & Polio & DTP & Measles & Mumps & Rubella \\
\hline \multirow[t]{2}{*}{ Total } & 1980 & $80.0 \%$ & $84.2 \%$ & & & \\
\hline & 1985 & 79.6 & 82.7 & & $\begin{array}{l}\text { These vaccines are not } \\
\text { recommended for }\end{array}$ & \\
\hline \multirow[t]{2}{*}{ White } & 1980 & 80.9 & 84.9 & & children of this age. & \\
\hline & 1985 & 81.5 & 84.4 & & & \\
\hline \multirow[t]{2}{*}{ Nonwhite } & 1980 & 73.2 & 79.0 & & & \\
\hline & 1985 & 58.5 & 64.8 & & & \\
\hline \multirow{3}{*}{$\begin{array}{l}\text { Age one } \\
\text { Total }\end{array}$} & & Polio & DTP & Measles & Mumps & Rubella \\
\hline & 1980 & $95.5 \%$ & $76.2 \%$ & & & \\
\hline & 1985 & 95.2 & 78.3 & & $\begin{array}{l}\text { These vaccines are not } \\
\text { recommended for }\end{array}$ & \\
\hline \multirow[t]{2}{*}{ White } & 1980 & 96.2 & 78.6 & & children of this age. & \\
\hline & 1985 & 96.9 & 80.1 & & & \\
\hline \multirow[t]{2}{*}{ Nonwhite } & 1980 & 89.1 & 56.5 & & & \\
\hline & 1985 & 82.3 & 64.9 & & & \\
\hline \multirow{3}{*}{$\begin{array}{l}\text { Age two } \\
\text { Total }\end{array}$} & & Polio & DTP & Measles & Rubella & Mumps \\
\hline & 1980 & $80.7 \%$ & $87.0 \%$ & $83.0 \%$ & $83.2 \%$ & $80.2 \%$ \\
\hline & 1985 & 76.7 & 85.8 & 81.7 & 77.3 & 78.9 \\
\hline \multirow[t]{2}{*}{ White } & 1980 & 83.0 & 89.4 & 84.8 & 84.4 & 81.5 \\
\hline & 1985 & 79.5 & 88.0 & 82.7 & 78.6 & 80.8 \\
\hline \multirow[t]{2}{*}{ Nonwhite } & 1980 & 62.8 & 68.0 & 69.0 & 73.4 & 70.7 \\
\hline & 1985 & 56.5 & 69.1 & 74.7 & 66.9 & 64.2 \\
\hline
\end{tabular}

- Dosage levels are approximations of level needed to fully immunize a child of a given age: younger than age one, one or more doses of polio and DTP; at age one, one or more doses of polio and three or more doses of DTP; and at age two, three or more doses of polio and DTP and one dose of measles, rubella, and mumps vaccines.

- Data are from the U.S. Immunization Survey sample confirmed by parent consultation with an immunization record. 
care. ${ }^{18}$ Between 9 million and 11 million children are completely uninsured, either publicly or privately. ${ }^{19}$ More than 30 million Americans, two-thirds of whom are women of childbearing age and children, live in areas considered medically underserved by the federal government. ${ }^{20}$

\section{Health Insurance Coverage}

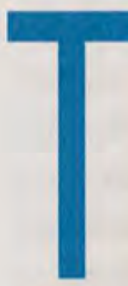

he federal government conducts periodic, special surveys of health insurance coverage among Americans. Two of the most important of these periodic surveys are the Health Interview Survey (HIS) and the Current Population Survey (CPS). The HIS is a special periodic national household study of Americans' health insurance and health care utilization patterns. The HIS is conducted by the U.S. Public
Table 24

PRICE INIFLATION FOR SELECTED CHILDHOOD VACCINES PURCHASED BY THE CENTERS FOR DISEASE CONTROL, 1981 AND 1991

$\begin{array}{lccc} & \begin{array}{c}\text { 1981 Price } \\ \text { Per Dose }\end{array} & \begin{array}{c}\text { May 1991 Price* } \\ \text { Per Dose }\end{array} & \text { Increase } \\ \begin{array}{c}\text { Diphtheria, Tetanus, } \\ \text { and Rubella (DTP) }\end{array} & \$ 0.150^{*} & \$ 6.245 & 4,063 \% \\ \text { Oral Polio Vaccine (OPV) } \$ 0.396 & \$ 2.001 & 405 \% \\ \begin{array}{c}\text { Measles, Mumps, } \\ \text { Rubella (MMR) }\end{array} & \$ 3.120 & \$ 15.329 & 391 \% \\ & & & \end{array}$

- 1991 prices include the following federal excise taxes: DTP - \$4.56, Polio - \$0.29, and MMR - \$4.44.

- No federal contract. Price listed is the approximate price negotiated by individual state health departments.

SOURCE: Centers for Disease Control.

\begin{tabular}{|c|c|c|c|c|c|c|c|c|}
\hline \multicolumn{9}{|c|}{$\begin{array}{l}\text { PERCENTAGE OF ONE-YEAR-OLD CHILDREN FULYY IMMUNIZED AGAINST } \\
\text { POLIO, SELECTED COUNIRIES, 1988-1989* }\end{array}$} \\
\hline Rank & Nation & Percentage & Rank & Nation & Percentage & Rank & Nation & tage \\
\hline 1 & Denmark & $100 \%$ & 22 & West Germany & $94 \%$ & 48 & Thailand & $84 \%$ \\
\hline 2 & Bulgaria & 99 & 27 & Israel & 93 & 48 & United Arab Emirates & 84 \\
\hline 2 & Czechoslovakia & 99 & 27 & Syria & 93 & 53 & Honduras & 83 \\
\hline 2 & Hungary & 99 & 27 & Tunisia & 93 & 53 & Iraq & 83 \\
\hline 2 & Poland & 99 & 30 & Columbia & 92 & 53 & Rwanda & 83 \\
\hline 6 & Greece & 98 & 30 & Kuwait & 92 & 56 & Burundi & 82 \\
\hline 6 & Sweden & 98 & 30 & Portugal & 92 & 56 & India & 82 \\
\hline 6 & Switzerland & 98 & 30 & Yugoslavia & 92 & 56 & Nicaragua & 82 \\
\hline 9 & Brazil & 97 & 34 & Costa Rica & 91 & 56 & Tanzania & 82 \\
\hline 9 & East Germany & 97 & 35 & Austria & 90 & & United States, Nonwhite & 82 \\
\hline 11 & China & 96 & 35 & Finland & 90 & 56 & Uruguay & 82 \\
\hline 11 & Hong Kong & 96 & 35 & Singapore & 90 & 62 & Algeria & 81 \\
\hline 11 & Mexico & 96 & 38 & Iran & 89 & 62 & Argentina & 81 \\
\hline 11 & North Korea & 96 & 38 & Malawi & 89 & 62 & Egypt & 81 \\
\hline 11 & Oman & 96 & 40 & Botswana & 88 & 62 & Lesotho & 81 \\
\hline 11 & Saudi Arabia & 96 & 40 & Mauritius & 88 & 62 & Zambia & 81 \\
\hline 17 & Belgium & 95 & 42 & South Korea & 87 & 67 & USSR & 80 \\
\hline 17 & Chile & 95 & 42 & Sri Lanka & 87 & 68 & Trinidad and Tobago & 77 \\
\hline 17 & France & 95 & 42 & United Kingdom & 87 & 69 & New Zealand & 75 \\
\hline 17 & Romania & 95 & 45 & Canada & 85 & 70 & Spain & 73 \\
\hline 17 & United States & 95 & 45 & Italy & 85 & 71 & Ireland & 72 \\
\hline 22 & Albania & 94 & 45 & Mongolia & 85 & 71 & Malaysia & 72 \\
\hline 22 & Cuba & 94 & 48 & Jamaica & 84 & 73 & Panama & 71 \\
\hline 22 & Jordan & 94 & 48 & Libya & 84 & 73 & Paraguay & 71 \\
\hline 22 & Netherlands & 94 & 48 & Norway & 84 & 75 & Venezuela & 67 \\
\hline
\end{tabular}

- Data are for 1988-1989 for all countries except the United States. Most recent U.S. data available are for 1985 because the nation no longer conducts the necessary surveys.

SOURCE: UNICEF. United States nonwhite rate from the U.S. Immunization Survey, 1985. 
Health Service, and in 1988 it included a special Child Health Survey. The CPS is an annual household interview survey conducted by the U.S. Census Bureau, which examines Americans' insurance status. This edition of The Health of America's Children presents statistics from both the HIS and the CPS.

\section{Health Insurance Stafus of Children}

HIS data for 1988 show that 83.1 percent of the nearly 64 million American children younger than 18 were covered by either a private health insurance plan or by Medicaid. The remaining 10.8 million were completely uninsured, either publicly or privately, or had unknown insurance status. Children least likely to be covered were infants younger than one, children of Latino origin, and children with annual family incomes of less

Table 26

\section{CHILDREN'S HEALTH INSURANCE COVERAGE, BY SELECTED CHARACTERISTCS, U.S., 1988}

\begin{tabular}{|c|c|c|c|c|}
\hline & \multicolumn{2}{|c|}{$\begin{array}{l}\text { Insured by Public } \\
\text { or Private Plan }\end{array}$} & \multicolumn{2}{|c|}{$\begin{array}{l}\text { Uninsured or Unknown } \\
\text { Insurance Status * }\end{array}$} \\
\hline & Percent & $\begin{array}{l}\text { Number } \\
\text { (thousands) }\end{array}$ & Percent & $\begin{array}{l}\text { Number } \\
\text { (thousands) }\end{array}$ \\
\hline All children & $83.1 \%$ & 52,812 & $16.9 \%$ & 10,757 \\
\hline \multicolumn{5}{|l|}{ Race } \\
\hline White & $83.7 \%$ & 43,025 & $16.3 \%$ & 8,355 \\
\hline Black & $80.9 \%$ & 7,943 & $19.1 \%$ & 1,877 \\
\hline \multicolumn{5}{|l|}{ Ethnicity } \\
\hline Latino & $70.0 \%$ & 5,069 & $30.0 \%$ & 2,170 \\
\hline Non-Latino & $84.9 \%$ & 46,714 & $15.1 \%$ & 8,317 \\
\hline \multicolumn{5}{|l|}{ Income } \\
\hline Less than $\$ 10,000$ & $71.8 \%$ & 5,689 & $28.2 \%$ & 2,235 \\
\hline$\$ 10,000$ to $\$ 24,999$ & $76.1 \%$ & 12,721 & $23.9 \%$ & 3,987 \\
\hline$\$ 25,000$ to $\$ 39,999$ & $89.8 \%$ & 14,133 & $10.2 \%$ & 1,604 \\
\hline Greater than $\$ 40,000$ & $92.4 \%$ & 14,848 & $7.6 \%$ & 1,223 \\
\hline \multicolumn{5}{|l|}{ Age } \\
\hline Younger than 1 & $80.1 \%$ & 3,082 & $19.9 \%$ & 768 \\
\hline Ages 1 to 4 & $83.7 \%$ & 12,170 & $16.3 \%$ & 2,366 \\
\hline Ages 5 to 7 & $83.3 \%$ & 9,197 & $16.7 \%$ & 1,840 \\
\hline Ages 8 to 11 & $83.8 \%$ & 11,424 & $16.2 \%$ & 2,211 \\
\hline Ages 12 to 14 & $83.0 \%$ & 8,189 & $17.0 \%$ & 1,683 \\
\hline Ages 15 to 17 & $82.3 \%$ & 8,751 & $17.7 \%$ & 1,888 \\
\hline \multicolumn{5}{|l|}{ Health status } \\
\hline Fair or poor health & $78.0 \%$ & 1,394 & $22.0 \%$ & 394 \\
\hline \multicolumn{5}{|c|}{$\begin{array}{l}\text { Available data from NCHS did not separate estimates of children without health in- } \\
\text { surance coverage from those with unknown insurance status. }\end{array}$} \\
\hline $\begin{array}{l}\text { SOURCE: National Healt } \\
\text { Children's Defense Fund }\end{array}$ & rview S & on Child $\mathrm{Hc}$ & Ith. Calculati & $y$ the \\
\hline
\end{tabular}

than $\$ 25,000$. Children in only fair to poor health also were less likely to be insured than those in good to excellent health (Table 26).

Until they reach adolescence, black and white children are equally likely to be covered by some form of public or private health insurance. However, during adolescence, coverage among black children begins to decline in relation to that of white children. This is because of the important differences that underlie the overall insurance patterns for black and white children (Table 27).

CPS data from 1986 reveal the degree to which black children - even black children in working families - depend on Medicaid. In 1986 nearly 15 percent of black children in employed families, compared with only 5 percent of white children in employed families, relied exclusively on Medicaid for their health insurance coverage. That year less than half of all black children living in working families, compared with nearly 70 percent of white children in employed families, had employer coverage (Table 28).

Black children's reduced access to private health insurance (more than 90 percent of which is derived through employer plans in the case of children) and greater reliance on Medicaid is a reflection of their far greater poverty levels, their greater tendency to live with only one parent (thereby reducing significantly the chance that they will have employer coverage through at least one of two parents), and the substantially lower paying jobs held by employed black adults with children. While poverty and living with a single parent significantly increase the likelihood of Medicaid coverage for black children during infancy and early childhood, these factors also may diminish the likelihood of Medicaid coverage for older children, as their eligibility for AFDC falls. For black children there is far less chance that the insurance gap caused by the loss of Medicaid will be filled by employer coverage.

Employer insurance, perhaps the most important form of employee compensation after wages themselves, is a fringe benefit disproportionately enjoyed by higher income wage earners. Children in lower income working families are far less likely to have employer provided coverage either because their parents are themselves ineligible for work-related benefits or else because their parents' 
employers, while making coverage available, do not contribute to the cost of dependent coverage. For lower income working families, the cost of covering children (which easily can amount to between $\$ 200$ and $\$ 300$ per month) is sufficiently prohibitive to preclude dependent coverage. From 1982 to 1988 the proportion of medium- and large-sized employers fully underwriting the cost of dependent coverage fell from 51 percent to less than 40 percent.

Black children who live in employed families are significantly more likely to have parents whose annual incomes are low. In 1986, 21 percent of all children in working families with incomes less than twice the federal poverty level were black, a number substantially higher than the proportion of all American children who are black. As a result, black children in working families are less likely to have employer coverage. Moreover, even when family incomes are identical, the CPS data show that black children in employed families are less likely than white children to be insured privately. These statistics suggest that even when black families achieve greater levels of income, the jobs they hold are not those that tend to furnish employer-provided benefits.

Health insurance coverage has a significant impact on children's use of health services. At every age, but particularly among older children, insured children were significantly more likely than their uninsured counterparts to have a regular source of primary health care and were more likely to have made at least one preventive health visit during the year (Table 29). Similarly, low family income affects a child's chances of having a regular source of health care at every age level. Finally, and particularly disturbingly, black infants younger than one

Table 27

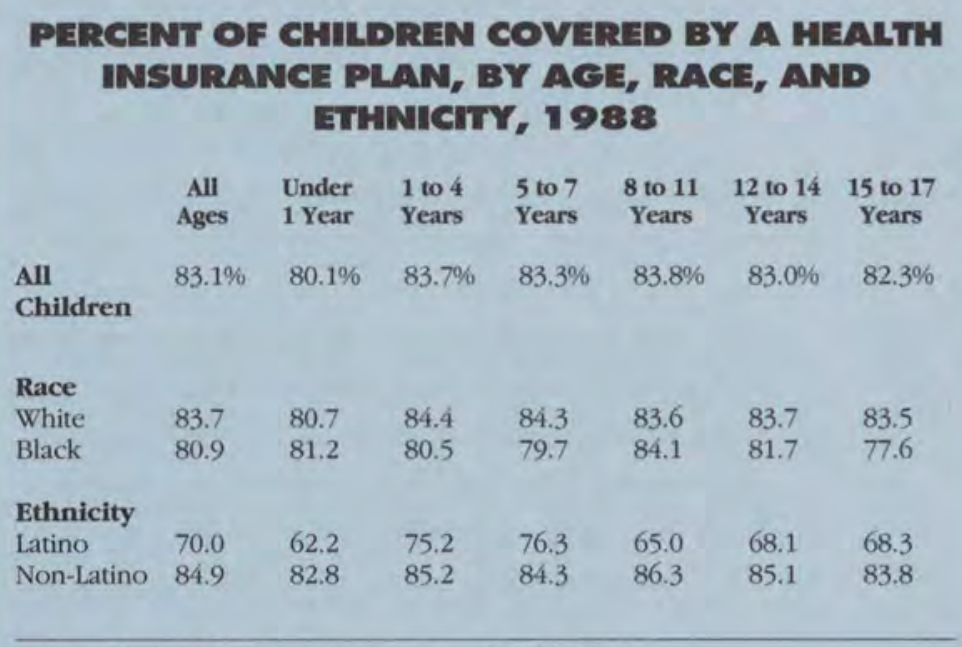

SOURCE: National Health Interview Survey of Child Health.

Table 28

\section{INSURANCE STATUS OF CHILDREN YOUNGER THAN 18 IN EMPLOYED FAMILIES, BY INCOME*, RACE, AND INSURANCE STATUS, U.S., 1986}

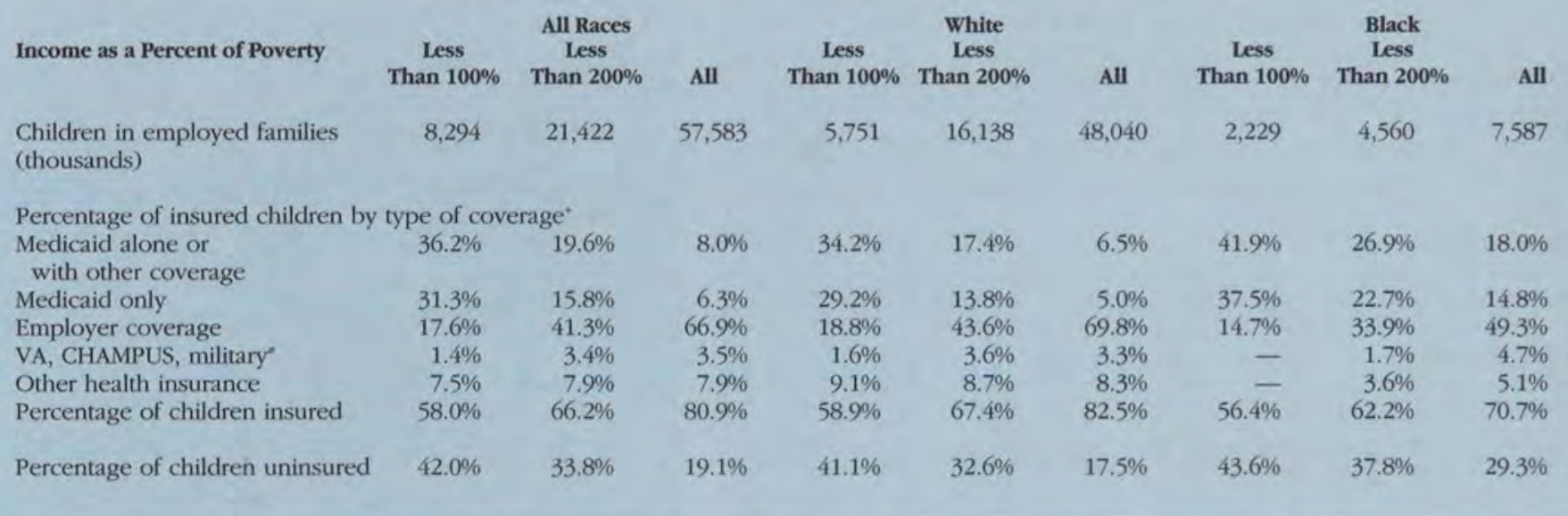

\footnotetext{
- Income measured as a percentage of the federal poverty level.

- Percentages may not equal 100 percent because some children have insurance from more than one source.

"The U.S. Department of Defense covers health care for members of the military and their dependents, including children, at military institutions and at civilian facilities.

SOURCE: Unpublished data from the U.S. Bureau of the Census, Current Population Survey. Calculations by the Children's Defense Fund.
} 
are significantly less likely than either white infants or infants of Latino origin to have a regular source of health care.

\section{Health Insurance Coverage Among Women of Childbearing Age}

In 1985 more than 9 million American women of childbearing age were completely uninsured, while another 5 million were uninsured for maternity care. ${ }^{21}$ Among women of childbearing age, those most likely to be completely uninsured are either unemployed or working at low-wage jobs. Black women and poor women are more likely to be uninsured (Table 30).

Lack of health insurance during pregnancy has a significant impact on women's use of maternity care. Uninsured women are less likely to begin care early, less likely to receive comprehensive care, and more likely to have late or no care. Highrisk women without maternity coverage have a far more difficult time obtaining the specialized care they need. ${ }^{22}$ This reduced access to care places both their lives and those of their infants at risk. This consequence is borne out in the significantly

Table 29

PERCENT OF CHILDREN WITH A REGULAR
SOURCE OF HEALTH CARE, BY AGE AND
SELECTED CHARACTERISTICS, U.S., 1988

\begin{tabular}{|c|c|c|c|c|c|c|c|}
\hline & $\begin{array}{c}\text { All } \\
\text { Under } 18\end{array}$ & $\begin{array}{l}\text { Under } \\
\text { Age } 1\end{array}$ & $\begin{array}{l}1 \text { to } 4 \\
\text { Years }\end{array}$ & $\begin{array}{l}5 \text { to } 7 \\
\text { Years }\end{array}$ & $\begin{array}{l}8 \text { to } 11 \\
\text { Years }\end{array}$ & $\begin{array}{l}12 \text { to } 14 \\
\text { Years }\end{array}$ & $\begin{array}{c}15 \text { to } 17 \\
\text { Years }\end{array}$ \\
\hline All children & $88.0 \%$ & $89.9 \%$ & $92.3 \%$ & $90.8 \%$ & $86.9 \%$ & $85.0 \%$ & $82.9 \%$ \\
\hline \multicolumn{8}{|l|}{ Race } \\
\hline White & 88.6 & 92.1 & 93.0 & 91.3 & 87.2 & 85.1 & 83.4 \\
\hline Black & 86.5 & 79.8 & 90.3 & 87.9 & 86.4 & 86.2 & 82.9 \\
\hline \multicolumn{8}{|l|}{ Latino origin } \\
\hline Latino & 81.1 & 88.2 & 89.2 & 82.1 & 81.6 & 72.6 & 72.2 \\
\hline Non-Latino & 88.9 & 89.8 & 92.9 & 91.9 & 87.6 & 86.6 & 84.2 \\
\hline \multicolumn{8}{|l|}{ Family income } \\
\hline Less than $\$ 10,00$ & 083.8 & 82.4 & 88.3 & 88.8 & 80.8 & 83.2 & 74.8 \\
\hline$\$ 10,000-\$ 24,999$ & 86.0 & 92.7 & 92.5 & 88.3 & 83.7 & 77.4 & 81.1 \\
\hline$\$ 25,000-\$ 39,999$ & 91.1 & 91.3 & 94.6 & 94.6 & 89.4 & 89.3 & 86.1 \\
\hline$\$ 40,000$ or more & 92.4 & 94.4 & 96.5 & 94.7 & 93.0 & 90.5 & 87.0 \\
\hline \multicolumn{8}{|c|}{ Health insurance status } \\
\hline Insured & 91.9 & 93.0 & 94.9 & 94.0 & 90.9 & 90.0 & 88.2 \\
\hline Not Insured & 79.0 & 85.7 & 88.5 & 83.4 & 75.6 & 70.3 & 70.7 \\
\hline
\end{tabular}

SOURCE: National Health Interview Survey of Child Health. elevated maternal and infant mortality rates seen among nonwhite women and infants, who also are the women and children most likely to be insured inadequately or not insured at all and who are the most likely to live in medically underserved areas.

Moreover, care during pregnancy alone cannot compensate completely for the accumulated ills caused by many years without adequate access to health care. A woman's capacity to have a healthy child is shaped substantially by her own health status as a child and young adult. In recent years important expansions in Medicaid coverage of lowincome pregnant women have been made, and these improvements are a critical step in promoting women's access to necessary maternity care. But women who enter pregnancy in poor health face far greater risks than women who have been able to obtain the care they need throughout child-

Table 30

PERCENTACE OF WOMEN AGES
15-44 WITHOUT PRIVATE HEALTH
INSURANCE, BY SELECTED
CHARACTERISTICS, 1985

Percentage Without Private Health Insurance

Total $17 \%$

Race/Ethnicity

Black

21

Latino

Marriage status Unmarried

Income

Less than $100 \%$ of poverty

More than $200 \%$ of poverty

Educational level

Less than 12 years 25

Age

15 to 19

20 to 24

22

Occupation

Service worker 28

Sales worker

Unskilled worker

Employment status

Unemployed

Part-time

Full-time

20

9 
hood and adulthood. Many of the conditions that can cause death or permanent disability in pregnant women and their infants (such as ectopic pregnancies, infections, and hypertension) emanate from conditions that were present well before pregnancy and that could have been controlled with routine health care.

\section{The Adequacy of Health Programs Serving Low- Income Women and Children}

\section{Reforms in Medicaid}

$\mathrm{n}$ response to declining levels of private coverage and the stagnation and erosion in key maternal and child health indicators, Congress in recent years has enacted significant expansions of the the Medicaid program. Together these recent reforms, among others:

- Require states to extend coverage to all pregnant women and children younger than six with family incomes below 133 percent of the federal poverty level; ${ }^{23}$

- Mandate phased-in coverage, on a year-byyear basis, of all children who have attained age six and who were born after September 30, 1983, are younger than 19 , and have family incomes below 100 percent of the federal poverty level; ${ }^{24}$

- Permit states, at their option, to extend coverage to all pregnant women and infants younger than one with family incomes below 185 percent of the federal poverty level. ${ }^{25}$

As of January 1991, 18 states had elected to cover all pregnant women and infants with incomes of less than 185 percent of poverty, and six states covered all pregnant women and infants with family incomes of more than 133 percent but less than 185 percent of poverty. The remaining states had not taken the option of covering some or all near-poor pregnant women and infants for whom coverage is discretionary under federal law (Figure 5).

If fully implemented, the Medicaid reforms for pregnant women and children will extend Medicaid coverage to more than 500,000 additional pregnant women and some 4 million children annually, making the program one of the largest sources of health care financing for maternity and pediatric health coverage. If high rates of childhood poverty are sustained, and if the nation fails to enact a national health program for all Americans, Medicaid increasingly will fill the enormous and growing gaps left by private coverage. By the end of this century, Medicaid can be expected to finance between one-third and one-half of all maternity and pediatric health care in the United States. Indeed, numerous states report that Medicaid already covers between 40 and 50 percent of all births.

Gaps in insurance coverage appear to be growing. Preliminary statistics show that between March 1988 and March 1989 the number of uninsured Americans climbed by another 2 million persons. The importance of Medicaid for pregnant women and children makes the program's shortcomings low provider reimbursement rates, complicated enrollment procedures, and unnecessarily restrictive eligibility standards - particularly disturbing. Many of these barriers could be eased now, yet states have not done so. For example, as of 1990 all states could, at their option: eliminate the use of any asset test for women, infants, and young children; use very short application forms; and institute presumptive (temporary) eligibility for pregnant women awaiting a final determination of Medicaid eligibility (which can take months to complete). Yet only one state - Massachusetts - took full advantage of all the options available to it (Table 31).

\section{Availability of Comprehensive Primary Health Services}

Health insurance significantly affects use of medical care. However, health insurance alone does not assure that appropriate and timely care will be accessible, particularly in the case of low-income persons living in communities with serious shortages of health providers. Millions of Americans - disproportionately children and women of childbearing age, members of racial and ethnic minorities, and low-income - live in isolated inner city and rural areas where critical shortages of comprehensive sources of primary health care exist. For these families, health care frequently is delayed until severe illness results, with rates of hospitalization for such conditions as pediatric asthma and pediatric gastroenteritis as much as 15 times greater than rates for nonpoor children living in communities with ad- 
equate levels of primary care. ${ }^{26}$ Infant mortality rates are elevated significantly, childhood immunization rates are depressed, and appropriate care arrangements for women and children with special health care needs are unavailable.

Studies have shown that achieving good health outcomes for low-income women and children involves both providing health insurance and having high-quality, accessible, and appropriate health services where they are needed..$^{27}$ Characteristics of successful service arrangements are their accessible locations; their high level of community involvement; their linguistic and cultural sensitivity; their capacity to furnish comprehensive care including medical, social, nutritional, and family supports and case management; and an administration style (such as special locations, evening hours, and bilingual staff) that actively promotes their accessibility. Stud- ies show that women and children who have access to comprehensive health services with these characteristics experience lower rates of preventable disease, lower mortality, and are more likely to use preventive health services. ${ }^{28}$

The federally funded Community and Migrant Health Centers programs embody these characteristics. These 540 federally supported clinics provide a broad array of medical and health-related services at some 2,000 service sites in severely medically underserved urban and rural communities in every state, the District of Columbia, and the U.S. territories. Their patients are overwhelmingly young and poor. In 1990 health centers served nearly 3 million children younger than 18 with family incomes below twice the federal poverty level (approximately one in every eight poor and near-poor children nationally). Health center patients accounted for more

Figure 5

\section{MAXIMUM MEDICAID INCOME ELIGIBILITY LEVELS FOR PREGNANT WOMEN AND INFANTS AS A PERCENTAGE OF THE FEDERAL POVERTY LEVEL, JANUARY 1991}

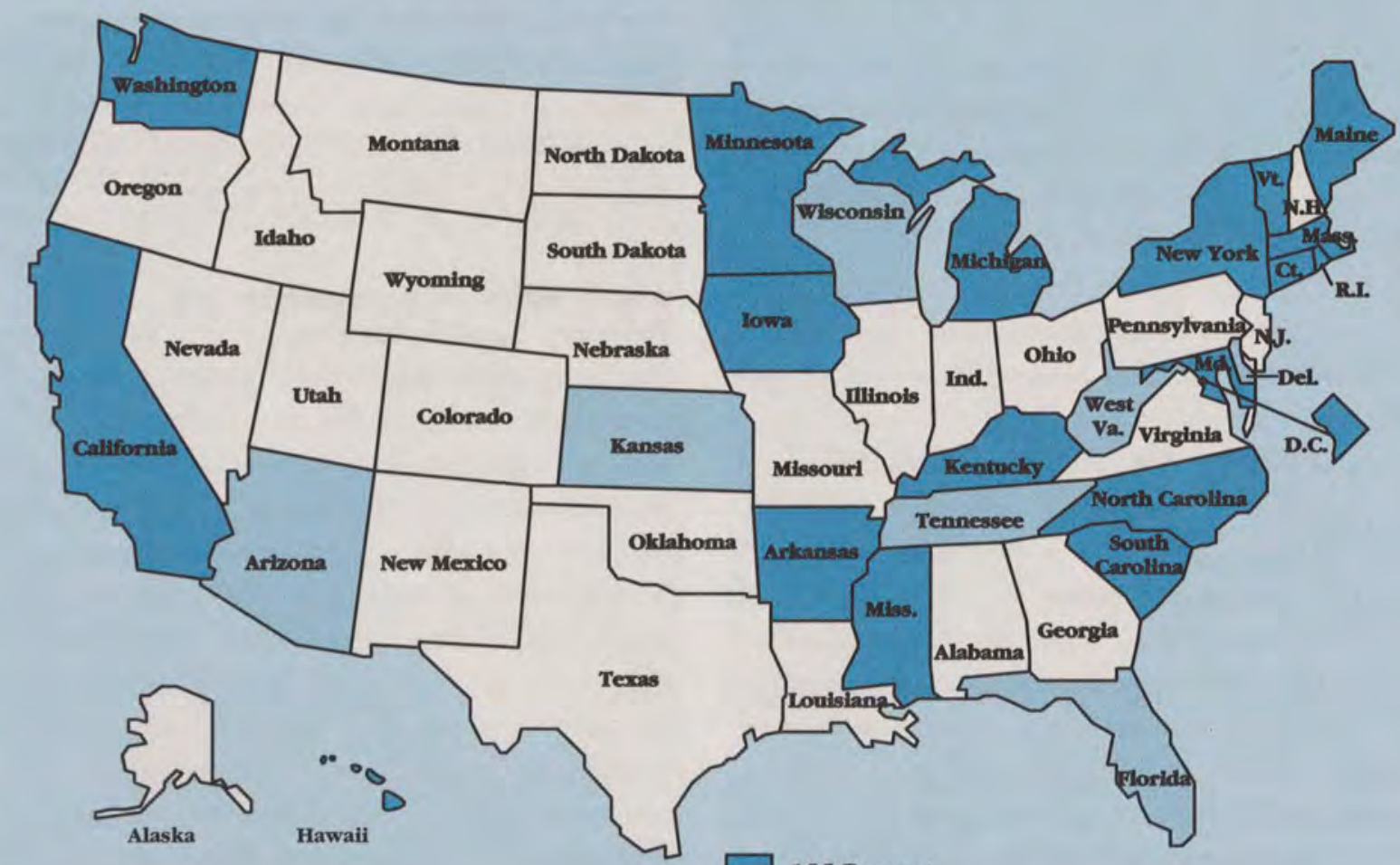

185 Percent 
than 10 percent of all births to low-income women in 1988 and more than 30 percent of all births to women younger than $15 .{ }^{29}$ As vital to the health of women and children as health centers are, their numbers fall far below the level of need. The 6 million patients served by health centers in 1990 represented only one in five medically underserved Americans.

A crucial companion program to health centers is the National Health Service Corps, which provides scholarship and loan repayment assistance to medical, nursing, and other health professionals in exchange for service in health professional shortage areas. (Health professional shortage areas are concentrated in communities designated as medically underserved because of high poverty rates and poor health status measures, such as elevated infant mortality). Members of the Corps represent a vital source of health care personnel for health centers, making up 25 percent of all health center medical staff in $1990 .{ }^{30}$ However, the funding level for the Corps is sufficient to assure only about one-quarter of the physicians needed to eliminate all health professional shortage areas. And even this figure understates the shortfall. These estimates of need (generated by the U.S. Public Health Service) are based on a physician-to-patient practice ratio of 1-to-3,500, even though the normal physician practice is approximately 1 -to- 1,800 .

Other important programs help fund comprehensive child health services to low-income women and children. The Title V Maternal and Child Health Services Block Grant provides funds to state health agencies for the development of health services for low-income women and children and for children with special health care needs. The federal Childhood Immunization Grants program funds the purchase and distribution of childhood vaccines to state and local health agencies, Community and Migrant Health Centers, and other sources of child health care. And the federal family planning program funds family planning services and supplies for low-income women of childbearing age.

With the exception of the childhood vaccine program, none of these programs even nominally has kept pace with inflation. Many are operating far below their 1981 real-dollar funding levels, although the number of uninsured and poor children has soared (Table 32 ). Even the childhood vaccine pro-
Table 31

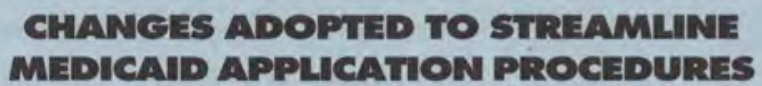

\begin{tabular}{|c|c|c|c|}
\hline State & $\begin{array}{l}\text { Eliminated } \\
\text { Assets Test }\end{array}$ & $\begin{array}{c}\text { Shortened } \\
\text { Application }\end{array}$ & $\begin{array}{c}\text { Presumptive } \\
\text { Eligibility }\end{array}$ \\
\hline Alabama & Yes & Yes & Yes \\
\hline Alaska & Yes & No & No \\
\hline Arizona & Yes & No & No \\
\hline Arkansas & Yes & Yes & Yes \\
\hline California & No & No & No \\
\hline Colorado & Yes & Yes & Yes \\
\hline Connecticut & Yes & No & No \\
\hline Delaware & Yes & Yes & No \\
\hline District of Columbia & Yes & No & No \\
\hline Florida & Yes & Yes & Yes \\
\hline Georgia & Yes & Yes & No \\
\hline Hawaii & Yes & No & Yes \\
\hline Idaho & Yes & No & Yes \\
\hline Illinois & No & No & Yes \\
\hline Indiana & Yes & No & Yes \\
\hline Iowa & No & No & Yes \\
\hline Kansas & Yes & No & No \\
\hline Kentucky & Yes & Yes & No \\
\hline Louisiana & Yes & Yes & Yes \\
\hline Maine & Yes & No & Yes \\
\hline Maryland & Yes & Yes & Yes \\
\hline Massachusetts & Yes & Yes & Yes \\
\hline Michigan & Yes & Yes & No \\
\hline Minnesota & Yes & Yes & No \\
\hline Mississippi & Yes, & No & No \\
\hline Missouri & Yes & No & Yes \\
\hline Montana & Yes & No & Yes \\
\hline Nebraska & Yes & No & Yes \\
\hline Nevada & Yes & No & No \\
\hline New Hampshire & Yes & No & No \\
\hline New Jersey & Yes & Yes & Yes \\
\hline New Mexico & Yes & Yes & Yes \\
\hline New York & Yes & Yes & Yes \\
\hline North Carolina & Yes & Yes & Yes \\
\hline North Dakota & No & No & No \\
\hline Ohio & Yes & Yes & No \\
\hline Oklahoma & Yes & Yes & Yes \\
\hline Oregon & Yes & Yes & No \\
\hline Pennsylvania & Yes & No & Yes \\
\hline Rhode Island & Yes & No & No \\
\hline South Carolina & Yes & Yes & No \\
\hline South Dakota & Yes & Yes & No \\
\hline Tennessee & Yes & No & Yes \\
\hline Texas & No & Yes & Yes \\
\hline Utah & Yes & No & Yes \\
\hline Vermont & Yes & Yes & No \\
\hline Virginia & Yes & Yes & No \\
\hline Washington & Yes & Yes & No \\
\hline West Virginia & Yes & Yes & No \\
\hline Wisconsin & Yes & Yes & Yes \\
\hline Wyoming & Yes & No & No \\
\hline Total & 46 & 27 & 26 \\
\hline
\end{tabular}

SOURCE: National Governors' Association 
gram, which shows a 10 -year nominal funding increase of 600 percent (Table 33), has fallen further and further behind the need as vaccine prices have escalated, as private physicians have ceased vaccinating children, as poverty has skyrocketed among preschool children, and as the number of children dependent on sources of publicly administered vaccines consequently has increased.

\section{Special Supplemental Food Program for Women, Infants, and Children (WIC)}

Enacted in 1972, WIC is one of the most effective health programs ever created. The health care and food supplements it provides to pregnant women, breastfeeding mothers, infants, and young

Table 32

REAL DOLLAR FUNDING FOR KEY PUBLC HEALTH PROGRAMS, FY 1981 TO 1991

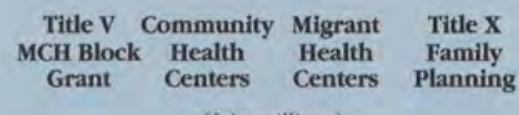

( $\$$ in millions)

FY 1981 Appropriation

$\$ 457 \quad \$ 323 \quad \$ 43$

$\$ 161$

FY 1991 Appropriation Needed

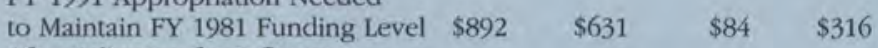
After Adjusting for Inflation *

Actual FY 1991

Appropriation

$\$ 478$

$\$ 52$

$\$ 144$

Funding Change in Real Dollars

$-34 \%$

$-24 \%$

$-38 \%$

$-54 \%$

Inflation based on the Consumer Price Index for Urban Consumers (CPI-U) for medical care costs.

SOURCE: Children's Defense Fund.

Table 33

ACTUAL FUNDING LEVELS FOR FEDERAL VACCINE PROCRAM, SELECTED FISCAL YEARS

Fiscal Year

1981

1987

1990

1991

Percent Increase, FY 1981 to FY 1991: 601\% children have had a major impact on the women and children the program reaches. Savings of $\$ 2$ to $\$ 3$ have been measured for every $\$ 1$ spent on WIC during pregnancy. ${ }^{31}$

Yet in FY 1991 the program reached only half the women and children who needed it. In 1990 only 19 states and the District of Columbia (Table 34) appropriated state funds to supplement the federal WIC funds they received. The high cost of food, high levels of poverty, and the poor nutritional status of many low-income women and children make the unmet need for WIC greater than ever. Yet funding levels are estimated to be $\$ 1$ billion a year less than what is necessary to assure that the program fully meets the need.

\section{Progress Toward Meeting the Public Health Service Objectives for the Year 2000}

n September 1990 the U.S. Public Health Service issued a lengthy series of health objectives for the nation for the year 2000. In establishing new goals for the year 2000 , the federal government has reaffirmed the need for national objectives to spur the nation to action on behalf of children. Building on goals for 1990 originally set in 1979 by the Surgeon General of the United States, ${ }^{32}$ these objectives set a series of health status, risk reduction, and health services and protection goals for Americans of all ages. ${ }^{33}$ Many of the objectives pertain to children.

The nation has failed to meet many of the most crucial child health goals set in 1979 for 1990. Failure to make progress in improving maternal, infant, and child health measures throughout the 1980 s means that the nation has not met the modest 1990 goals for infant mortality, low birthweight, prenatal care, and childhood immunization..$^{34}$

The year 2000 goals themselves are a testament to the stagnation and erosion in key maternal and child health indicators that persisted throughout the 1980s. For example, the year 2000 goals for infant low birthweight, prenatal care, and childhood immunization are identical to those set for 1990 . The year 2000 infant mortality goal, according to the

SOURCE: Children's Defense Fund.

Millions

$\$ 31.0$

$\$ 217.2$ 
Public Health Service, reflects the same slow rate of progress in reducing infant deaths that the nation experienced over the past decade, ${ }^{35}$ a rate far slower than in the 1970s. In this respect some of the goals are not aggressive enough. Yet certain indicators of maternal and child health are moving so slowly in the right direction (or else are not moving at all or are moving in the wrong direction) that without new and aggressive efforts by national, state, and lo$\mathrm{cal}$ governments and local communities, even these extremely modest goals will not be met.

In this section of the report, $\mathrm{CDF}$ has calculated how rapidly the nation and the states are moving toward the year 2000 objectives in key areas of maternal and child health. In calculating the nation's and states' rates of progress, CDF used trend data from 1978 through 1988. The calculations, therefore, are extremely conservative and tend to be overly optimistic about progress toward goals, since projections are based on the average annual rate of progress made between 1978 and 1988, including the 1978-1981 period, when the rate of progress was far more rapid than the 1981-1988 period (Tables 35, 36, 37). The U.S. Public Health Service, in setting the year 2000 goals, assumed that progress will continue through the 1990 s only at its slowed 1980 s pace. Because the Public Health Service uses a slower rate of progress, CDF also has included goal calculations using the 1981-1988 average annual rate of progress. For childhood immunizations, calculations go only through 1985 , because the government ceased collecting data then after a marked downward trend in immunization.

\section{Year 2000 Objective for Infant Mortality}

By the year 2000 the national infant mortality rate should be no more than 7.0 deaths per 1,000 live births, and mortality among black infants should be no greater than 11.0 deaths per 1,000 live births.

The average annual national rate of progress in reducing infant mortality between 1978 and 1988 means that the year 2000 objectives will be met both overall and for black infants. However, if a 1981-1988 average annual rate of progress is used, the goals will not be met and the nation will fall far short of the black goal, in particular.

Even if the overall and black infant mortality goals are met nationally, this would not be univer-
Table 34

\section{PERCENTAGE OF WIC ELIGIBLES SERVED, MARCH 1991}

\begin{tabular}{|c|c|c|c|c|}
\hline & $\begin{array}{c}\text { Estimated } \\
\text { Number of } \\
\text { Eligible } \\
\text { Persons, FY } 1991\end{array}$ & $\begin{array}{c}\text { Number } \\
\text { of WIC } \\
\text { Participants }\end{array}$ & $\begin{array}{c}\text { Percentage } \\
\text { of Eligibles } \\
\text { Served }\end{array}$ & $\begin{array}{l}\text { Does State } \\
\text { Supplemen } \\
\text { Federal } \\
\text { Funds? }\end{array}$ \\
\hline Alabama & 189,000 & 107,548 & $57 \%$ & No \\
\hline Alaska & 16,000 & 8,930 & $56 \%$ & Yes \\
\hline Arizona & 120,000 & 73,867 & $64 \%$ & No \\
\hline Arkansas & 120,000 & 60,470 & $50 \%$ & No \\
\hline California & 856,000 & 451,220 & $53 \%$ & No \\
\hline Colorado & 93,000 & 45,860 & $58 \%$ & No \\
\hline Connecticut & 71,000 & 56,142 & $79 \%$ & Yes \\
\hline Delaware & 20,000 & 11,032 & $55 \%$ & Yes \\
\hline District of Columbia & 21,000 & 14,200 & $88 \%$ & Yes \\
\hline Florida & 329,000 & 207,108 & $63 \%$ & No \\
\hline Georgia & 252,000 & 168,821 & $67 \%$ & No \\
\hline Hawaii & 43,000 & 14,885 & $35 \%$ & Yes \\
\hline Idaho & 57,000 & 22,919 & $40 \%$ & No \\
\hline Illinois & 351,000 & 207,685 & $61 \%$ & Yes \\
\hline Indiana & 185,000 & 116,612 & $63 \%$ & Yes \\
\hline Iowa & 94,000 & 47,633 & $51 \%$ & Yes \\
\hline Kansas & 83,000 & 40,716 & $50 \%$ & No \\
\hline Kentucky & 169,000 & 92,150 & $55 \%$ & No \\
\hline Louisiana & 207,000 & 121,009 & $67 \%$ & No \\
\hline Maine & 48,000 & 25,251 & $53 \%$ & No \\
\hline Maryland & 108,000 & 64,368 & $60 \%$ & No \\
\hline Massachusetts & 145,000 & 77,100 & $53 \%$ & Yes \\
\hline Michigan & 282,000 & 168,281 & $71 \%$ & Yes \\
\hline Minnesota & 118,000 & 76,020 & $66 \%$ & Yes \\
\hline Mississippi & 158,000 & 108,422 & $69 \%$ & No \\
\hline Missouri & 173,000 & 79,237 & $46 \%$ & No \\
\hline Montana & 34,000 & 16,496 & $49 \%$ & No \\
\hline Nebraska & 57,000 & 26,160 & $50 \%$ & No \\
\hline Nevada & 23,000 & 16,021 & $70 \%$ & No \\
\hline New Hampshire & 27,000 & 15,750 & $64 \%$ & Yes \\
\hline New Jersey & 190,000 & 104,273 & $55 \%$ & Yes \\
\hline New Mexico & 75,000 & 33,552 & $49 \%$ & No \\
\hline New York & 613,000 & 363,968 & $60 \%$ & Yes \\
\hline North Carolina & 238,000 & 138,489 & $58 \%$ & Yes \\
\hline North Dakota & 28,000 & 16,550 & $59 \%$ & No \\
\hline Ohio & 345,000 & 195,726 & $57 \%$ & No \\
\hline Oklahoma & 127,000 & 52,170 & $41 \%$ & No \\
\hline Oregon & 88,000 & 47,004 & $54 \%$ & No \\
\hline Pennsylvania & 338,000 & 229,381 & $68 \%$ & Yes \\
\hline Rhode Island & 27,000 & 17,659 & $65 \%$ & No \\
\hline South Carolina & 147,000 & 104,378 & $71 \%$ & No \\
\hline South Dakota & 37,000 & 19,516 & $54 \%$ & No \\
\hline Tennessee & 192,000 & 111,073 & $62 \%$ & No \\
\hline Texas & 638,000 & 367,618 & $58 \%$ & Yes \\
\hline Utah & 101,000 & 39,203 & $39 \%$ & No \\
\hline Vermont & 20,000 & 16,507 & $83 \%$ & No \\
\hline Virginia & 174,000 & 96,853 & $56 \%$ & No \\
\hline Washington & 132,000 & 62,295 & $47 \%$ & Yes \\
\hline West Virginia & 77,000 & 38,929 & $51 \%$ & Yes \\
\hline Wisconsin & 135,000 & 78,988 & $59 \%$ & Yes \\
\hline Wyoming & 14,000 & 9,008 & $64 \%$ & No \\
\hline U.S. Total & $8,580,000$ & $4,815,078$ & $57 \%$ & \\
\hline
\end{tabular}

SOURCE: Center on Budget and Policy Priorities 
Table 35

\section{National Progress Since 1978}

\section{SURGEON GENERAL'S YEAR 2000 MATERNAL AND INFANT MEALTH GOALS}

\begin{tabular}{lccccc}
\multicolumn{4}{c}{ Point Change Per Year } \\
1988 & Will the & When Will \\
Rate & Goal & Actual & Needed & $\begin{array}{c}\text { Goal Be } \\
\text { Goal Be }\end{array}$ \\
1978-88 & $1988-2000$ & Met by 2000? & Met?
\end{tabular}

Early Prenatal Care

\begin{tabular}{|c|c|c|c|c|c|c|}
\hline All races & 75.9 & 90.0 & 0.10 & 1.17 & No & 2129 \\
\hline Black & 61.1 & 90.0 & 0.09 & 2.41 & No & 2309 \\
\hline \multicolumn{7}{|c|}{ Low Birthweight } \\
\hline All races & 6.9 & 5.0 & -0.02 & -0.16 & No & 2083 \\
\hline Black & 13.0 & 9.0 & 0.01 & -0.67 & No & Wrong direction \\
\hline \multicolumn{7}{|c|}{ Infant Mortality } \\
\hline All races & 10.0 & 7.0 & -0.38 & -0.25 & Yes & 1996 \\
\hline Black & 17.6 & 11.0 & -0.55 & -0.55 & Yes & 2000 \\
\hline \multicolumn{7}{|c|}{ Neonatal Mortality } \\
\hline All races & 6.3 & 4.5 & -0.32 & -0.15 & Yes & 1994 \\
\hline Black & 11.5 & 7.0 & -0.40 & -0.38 & Yes & 1999 \\
\hline \multicolumn{7}{|c|}{ Postneonatal Mortality } \\
\hline All races & 3.6 & 2.5 & -0.07 & -0.09 & No & 2004 \\
\hline Black & 6.2 & 4.0 & -0.14 & -0.18 & No & 2004 \\
\hline
\end{tabular}

SOURCE: Children's Defense Fund

Table 36

National Progress Since 1981

\section{SURCEON GENERAL'S YEAR 2000 MATERNAL AND INFANT HEALTH GOALS}

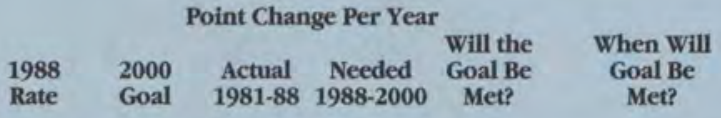

Early Prenatal Care

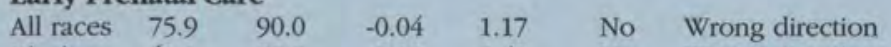

$\begin{array}{llllll}\text { Black } & 61.1 & 90.0 & -0.13 & 2.41 & \text { No }\end{array}$ Wrong direction

Low Birthweight

$\begin{array}{lllllll}\text { All races } & 6.9 & 5.0 & 0.01 & -0.16 & \text { No Wrong direction }\end{array}$

$\begin{array}{llllll}\text { Black } & 13.0 & 9.0 & 0.05 & -0.67 & \text { No }\end{array}$

Infant Mortality

$\begin{array}{lllllll}\text { All races } & 10.0 & 7.0 & -0.19 & -0.25 & \text { No } & 2004\end{array}$

$\begin{array}{llllll}\text { Black } & 17.6 & 11.0 & -0.24 & -0.55 \quad \text { No } & 2016\end{array}$

Neonatal Mortality

$\begin{array}{lllllll}\text { All races } & 6.3 & 4.5 & -0.17 & -0.15 & \text { Yes } & 1999\end{array}$

$\begin{array}{lllllll}\text { Black } & 11.5 & 7.0 & -0.19 & -0.38 & \text { No } & 2012\end{array}$

Postneonatal Mortality

$\begin{array}{lllllll}\text { All races } & 3.6 & 2.5 & -0.03 & -0.09 & \text { No } & 2025\end{array}$

$\begin{array}{lllllll}\text { Black } & 6.2 & 4.0 & -0.04 & -0.18 & \text { No } & 2043\end{array}$

sally true for states. Many states' average annual rate of progress has been too slow, and the overall goal for infant mortality will be met by only 40 states under the optimistic scenario. Ten states and the District of Columbia will not meet the goal.

\section{Year 2000 Objective for Infant Low Birthweight}

By the year 2000, no more than 5 percent of all infants should be born at low birthweight. No more than 9 percent of black infants should be born at low birthweight.

Using the 1978-1988 rate of progress, the nation's rate of progress has been so slow that neither the overall goal of 5 percent nor the goal for black infants of 9 percent will be met. At that rate the overall goal will not be met until the year 2083 . The low-birthweight goal for black infants never will be met because we are moving in the wrong direction. If the 1981-1988 time period is used, the nation never will meet either goal because it is moving in the wrong direction.

States' rates of progress have been so slow that only nine states will meet the overall year 2000 lowbirthweight goal.

\section{Year 2000 Goal for Prenatal Care}

By the year 2000, 90 percent of all pregnant women should begin prenatal care during the first three months of pregnancy.

At the 1978-1988 average annual rate of change, the nation's progress has been so slow that the goal will not be met. The year 2000 goal finally would be met for all women only in the year 2129 . If black women are considered alone, the goal would be met in the year 2309. Using the 1981-1988 average annual rate of progress, the goals will never be met because the nation is moving in the wrong direction.

Among states, progress has been similarly nonexistent. At the current rate of progress no state will meet the prenatal care goal by the year 2000 .

\section{Goal for Childhood Immunizations}

By the year 2000, 90 percent of all children should have completed their basic immunization series by age two.

At the 1980-1985 rate of progress the nation never will meet the goal for immunizations because we are moving in the wrong direction (Table 23). 
Year 2000 Goal for Preventable Childhood Diseases

Measles and rubella should be reduced to zero cases, mumps should be reduced to no more than 500 cases per year, and pertussis should be reduced to no more than 1,000 cases per year.

At the current rate of progress the goal never will be met because of soaring numbers of cases of preventable childhood disease (Table 22).

\section{State and City Findings}

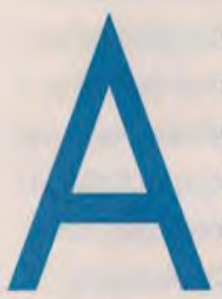

series of rankings and trend tables showing state-by-state maternal and infant health indicators for 1988 and for the 1978-1988 period is available from $\mathrm{CDF}$ as a separate Appendix to this report (contact CDF Publications for ordering information). The indicators are grouped into three series, each with health indicators for four groups: all races, white, black, and nonwhite women and infants. The Appendix also contains low-birthweight and infant mortality data for America's largest cities from 1988.

As in past years, there is tremendous variation from state to state in rates of infant mortality, low birthweight, and prenatal care use. The District of Columbia consistently displays the very worst maternal and infant health status, whether it is considered on an overall basis or for separate racial subgroups. The District's overall infant mortality rate ( 23.2 deaths per 1,000 live births) was more than three times as great as Vermont's ( 6.8 deaths per 1,000 live births), the state with the lowest rate. In fact, the District also ranked last among the nation's largest cities on infant mortality overall and for every racial subgroup (Table 38).

Yet, even those states that compare favorably against others do not perform well enough. For instance, Vermont's overall infant mortality rate was nearly 40 percent higher than Japan's. Similarly, the state with the best low-birthweight rate, South $\mathrm{Da}$ kota, had a low-birthweight rate no better than Egypt, Hong Kong, or Iran.

The five worst states on infant mortality and low
Table 37

\section{SURGEON GENERAL'S YEAR 2000 MATERNAL AND INFANT HEALTH COALS}

Will The State Meet the Year 2000 Goal Based on Progress Between 1978 and 1988?

Infant Mortality Low Birthweight Early Prenatal Care

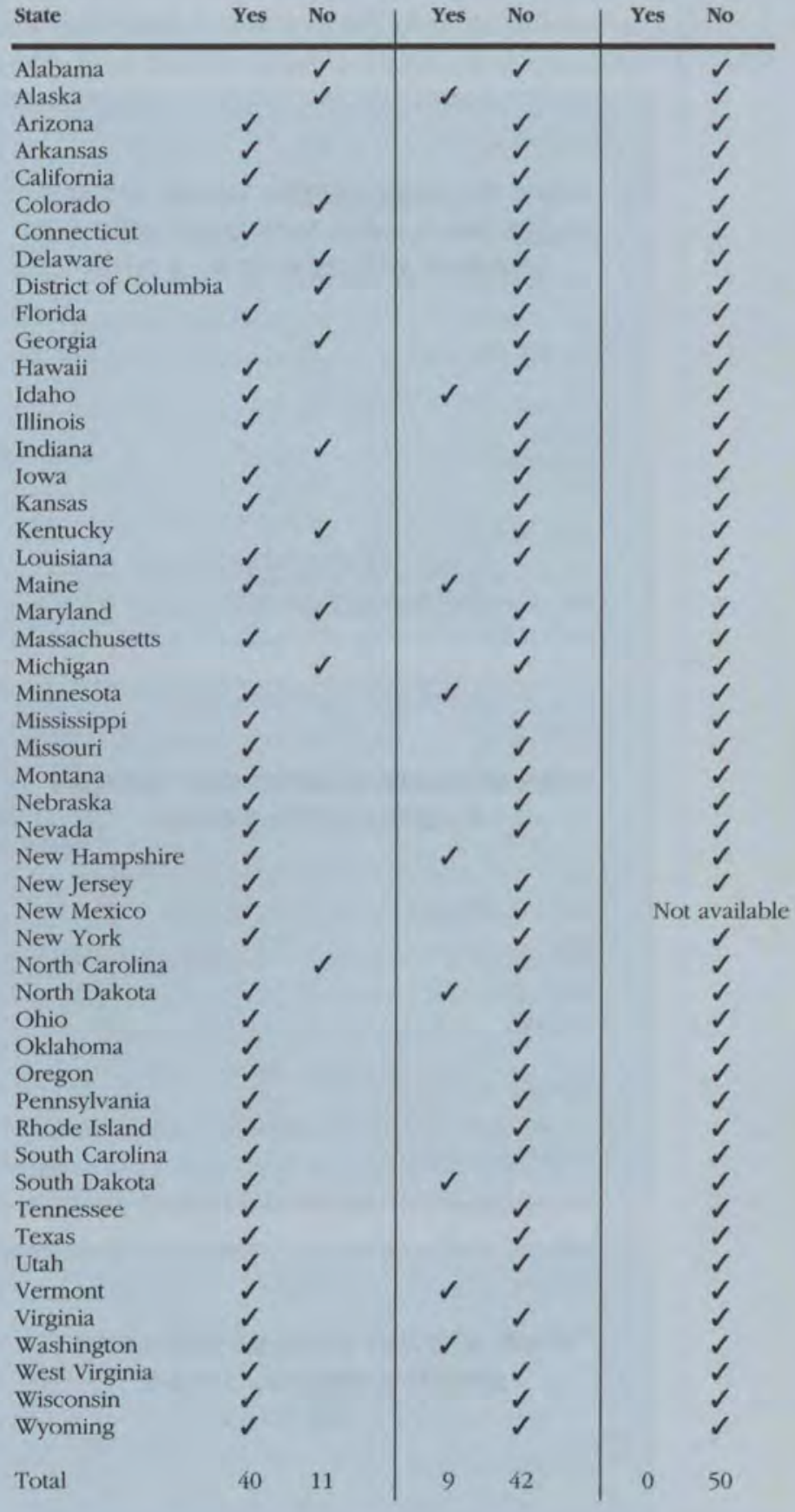

SOURCE: Children's Defense Fund. 
birthweight are all located in the Southern region (Tables 39 and 40). The poor rankings of Southern states on overall infant mortality and low birthweight primarily reflect the large black populations in those states who suffer terrible health status.

However, states in the South have been more active than others in improving maternal and child health in recent years. For instance, Southern states

Table 38

\section{FIVE WORST CITIES WITH MORE THAN 500,000 POPULATION ON INFANT MORTALTY, 1988}

City

District of Columbia

Detroit

Baltimore

Memphis

Philadelphia

- Deaths per 1,000 live births.

SOURCE: National Center for Health Statistics. Calculations by the Children's Defense Fund.

\section{Table 39 \\ FIVE WORST STATES ON INFANT MORTALITY, 1988}

State

District of Columbia

Rate*

Georgia

North Carolina

23.2

South Carolina

Mississippi

12.5

12.3

12.3

- Deaths per 1,000 live births.

SOURCE: National Center for Health Statistics. Calculations by the Children's Defense Fund.

Table 40

\section{FIVE WORST STATES ON LOW BIRTHWEIGHT, 1988}

\section{State}

District of Columbia

South Carolina

Louisiana

Mississippi

Georgia

\section{Percentage}

$14.3 \%$

9.0

8.8

8.7

8.4
SOURCE: National Center for Health Statistics. Calculations by the Children's Defense Fund. were among the first to implement options to expand Medicaid coverage for pregnant women and children. In contrast, Western states have been slower to respond. Among the five worst states in the proportion of births to women who received late or no prenatal care were New Mexico, Texas, and Arizona (Table 41). A Western state, Nevada, ranked sixth worst on late or no prenatal care, too.

\section{Conclusion and Recommendations}

he troubling findings in this report will not change until the nation as a whole commits to making the necessary investments in maternal and child health. Over the past several years some important federal reforms in publicly funded health programs for lowincome women and children have been enacted. Many states also have increased their commitment to maternal and child health services substantially. But these improvements have been outpaced by growing poverty, rising numbers of uninsured American women and children, and declining realdollar investment in basic public health activities.

For every dollar the nation has failed to invest early in the health of its children, it has lost much more in remedial health, education, and other costs. The White House Task Force on Infant Mortality estimated in 1989 that each infant death costs the nation $\$ 380,000$ in a lifetime of lost productivity. The report concluded that the nation would save $\$ 7$ billion per year by lowering its infant mortality rate to

Table 41

FIVE WORST STATES ON THE
PERCENTAGE OF INFANTS BORN
TO WOMEN RECEIVING LATE OR
NO PRENATAL CARE, I988

State

New Mexico

Texas

District of Columbia

Arizona

South Carolina

\section{Percentage} $16.1 \%$

11.5

11.2

10.2

10.1
SOURCE: National Center for Health Statistics. Calculations by the Children's Defense Fund. 
Japan's level, and that major improvements could be made simply by investing in comprehensive maternal and infant health care and programs of proven effectiveness such as Medicaid, Community and Migrant Health Centers, the National Health Service Corps, the Maternal and Child Health Services block grant, and others.

If we are to reach the year 2000 goals, these investments must begin now. Basic health care for women and children is something that no civilized society can deny either its citizens or itself. President of the United States George Bush campaigned in 1988 on a platform of comprehensive health care for all pregnant women and children. Numerous expert studies and reports, including those by Bush's own experts and those congressionally mandated, have called for major health care reforms to assure that women and children get the care they need. The only thing lacking is the will to make it happen now.

CDF recommends the following reforms:

- In the long term, enactment of a national health plan that includes at least immediate comprehensive health insurance for all women of child-bearing age and all children and that provides the resources to develop comprehensive primary health services in all the communities where they are needed.

- Until enactment of that plan, however, Medi-caid should be expanded to cover all pregnant women and children younger than 19 with family incomes below 200 percent of the federal poverty level. Congress should expand the number of Community and Migrant Health Centers steadily and increase the supply of National Health Service Corps physicians so that by the year 2000 , at the latest, all communities will have the clinics, physicians, nurses, and other health professionals they need.

- WIC should be fully funded immediately, and funding for the family planning and Title $\mathrm{V}$ Maternal and Child Health Service block grant programs should be at least doubled.

- The nation must establish a national vaccine program that assures adequate supplies of vaccine at affordable rates and that provides the staff and resources to maintain high childhood immunization levels in medically underserved communities. Local health fairs and day-long efforts to vaccinate children are all very important, but vaccinating children cannot be a periodic event. So basic a health service as childhood vaccines must become as integral a part of American life as Medicare and Social Security are.

- Finally, the nation must make a long-term commitment to eradicating childhood poverty. It is poverty that lies at the heart of so much preventable infant death and disability. Until poverty and the hopelessness that accompanies it are eradicated, the nation's maternal and child health indicators will continue to lag behind other industrialized nations.

This nation has shown tremendous capacity to mobilize resources at every level to address problems when they are understood to be crises. The health of our children is such a crisis and calls for a long-term, systematic commitment to reform by all Americans.

\section{Technical Notes}

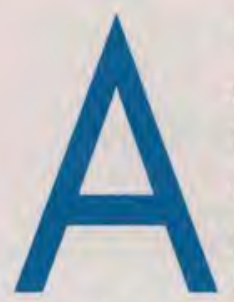

II U.S. mortality and natality data presented in this report are from the National Center for Health Statistics (NCHS), Data for international comparisons are drawn from UNICEF, The State of the World's Children, 1991.

NCHS data are based on all birth and death certificates registered in all 50 states and the District of Columbia. Most mortality and natality data presented are published in detailed tables contained in three volumes of Vital Statistics of the United States. Other mortality and natality data were obtained as unpublished tables from NCHS. All terms and definitions used in this report correspond to the definitions used by NCHS. The only exception is the use of the term "Latino" by CDF in place of NCHS' use of "Hispanic."

Data for Latino births and deaths are not reported by every state. For 1988, 31 jurisdictions reported the Latino origin of parents on birth certificates. These states were: Alabama, Arizona, Arkansas, California, Colorado, Connecticut, District of Columbia, Florida, Georgia, Hawaii, Illinois, Indiana, Kansas, Kentucky, Maine, Massachusetts, Mississippi, Montana, Nebraska, Nevada, New Jersey, 
New Mexico, New York, North Carolina, North Dakota, Ohio, Tennessee, Texas, Utah, Washington, and Wyoming. Only 27 jurisdictions reported Latino origin on death certificates for 1988: Alabama, Arizona, Arkansas, California, Colorado, District of Columbia, Georgia, Hawaii, Illinois, Indiana, Kansas, Kentucky, Maine, Mississippi, Montana, Nebraska, New Jersey, New York, North Carolina, North Dakota, Ohio, Oregon, Rhode Island, Texas, Utah, Washington, and Wyoming.

\section{Footnotes}

1. National Center for Health Statistics, "Advance Report of Final Mortality Statistics, 1988," Montbly Vital Statistics Report 39:4 (Supplement), August 15,1990 , p. 3.

2. Ibid, Table 4, p. 19.

3. Ibid, Table 18, p. 32

4. Ibid.

5. Children's Defense Fund, SOS Americal A Cbildren's Defense Budget (Washington, DC, 1990), p. 100.

6. U.S. Public Health Service, Health United States (1989) (PHS \#90-1232, Hyattsville, MD), p. 12.

7. Institute of Medicine, Preventing Low Birthweight (National Academy Press, Washington, DC, 1985)

8. Ibid.

9. Ibid.

10. Alan Guttmacher Institute, Blessed Events and the Bottom Line (NY, 1987), p. 11.

11. National Center for Health Statistics, "Births, Marriages, Divorces and Deaths for 1990," Montbly Vital Statistics Report 39:12, p. 3.

12. Ibid.

13. National Center for Health Statistics, "Advance Report of Final Mortality Statistics, 1988," Montbly Vital Statistics Report 39:7, p. 9.

14. Ibid.

15. Ibid, p. 11.

16. National Vaccine Advisory Committee, "The Measles Epidemic: The Problems, Barriers and Recommendations" (unpublished), January 16, 1991.
17. CDF, "Vaccine Supply and Low-Income Children: Barriers Faced by Community and Migrant Health Centers and Their Patients" (unpublished), May 1991.

18. Blessed Events, op. cit., p. 44.

19. Figures on the number of uninsured children vary widely depending on which study is used. For example, the 1988 Health Interview Survey (HIS), a national sample household study conducted by the U.S. Public Health Service, places the number of children with either no or unknown insurance status at 10.7 million. The national Medical Expenditure Survey, another national household survey conducted in 1987 by the U.S. Public Health Service, estimates the number of uninsured children at more than 11 million that year. Finally, the U.S. Bipartisan Commission on Health Care (the Pepper Commission) in its final 1990 report, A Call to Action, estimated that the number of uninsured children had fallen to about 9 million in 1990 as a result of Medicaid expansions enacted during the 1980s. Regardless of the study used, the number of uninsured children is appalling, especially in a nation like the U.S., in which access to even basic care turns on an individual's insurance status.

20. National Association of Community Health Centers, Access to Community Health Care, 1991 (Washington, DC).

21. Blessed Events, op. cit., p. 44.

22. Institute of Medicine, Prenatal Care: Reaching Mothers, Reaching Infants (National Academy Press, Washington, DC, 1988).

23. Omnibus Budget Reconciliation Act of 1989, P.L. 101-239, Sec. 6401 (effective April 1, 1990).

24. Omnibus Budget Reconciliation Act of 1990, P.L. 101-508, Sec. 4601 (effective July 1, 1991).

25. Omnibus Budget Reconciliation Act of 1987, P.L. 100-203, Sec. 4104 (effective July 1, 1988).

26. Valdez, R. and Dallele, G., "Does the Health System Serve Black and Latino Communities in Los Angeles County?" (unpublished, February 1991, University of California at Los Angeles).

27. Schlesinger, Mark and Kronebush, Karl, "The Failure of Prenatal Care Policy for the Poor," Healtb Affairs 9:4 (Winter 1990).

28. Prenatal Care: Reaching Women, op. cit.

29. Access to Community Healtb Care, op. cit.

30. Ibid.

31. Food and Nutrition Service, U.S. Department of Agriculture, "The Savings in Medicaid Costs for Newborns and Their Mothers from Prenatal Participation in the WIC Program" (October 1990),

32. U.S. Public Health Service, "Healthy People: The Surgeon General's Report to the Nation" (1979).

33. U.S. Public Health Service, "Healthy People, 2000," (1990).

34. Ibid.

35. Ibid,

36. For a separate review of selected 1987 maternal and infant health indicators for all U.S. cities with populations of 100,000 or greater, please order The Health of America's Children: The City Report (CDF, 1991). 


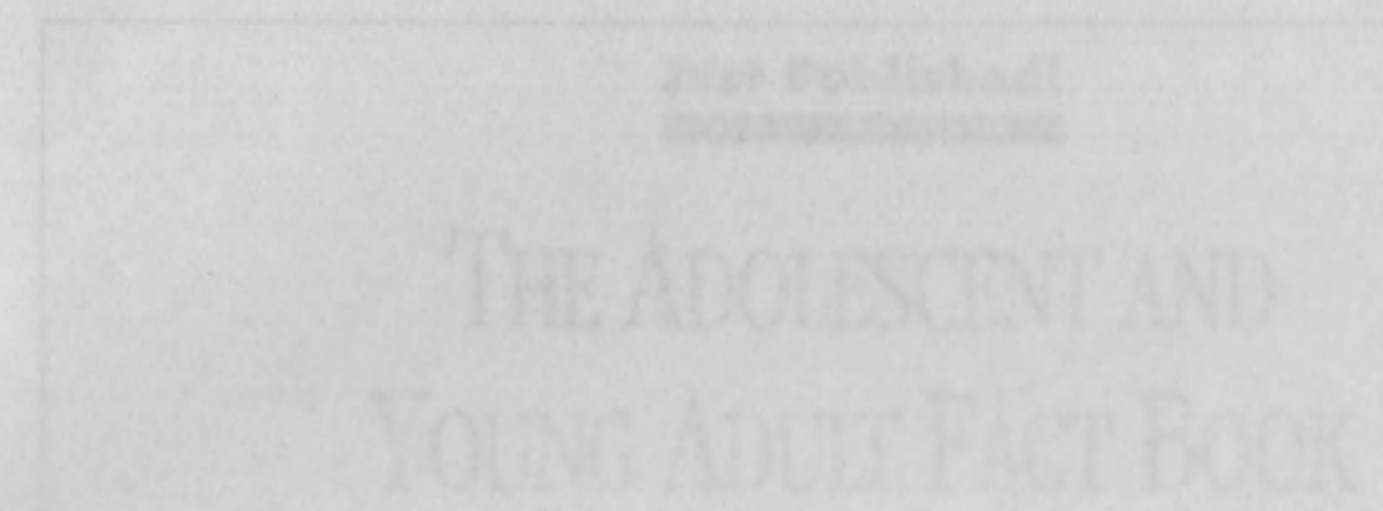





\section{Just Published! \\ THE ADOLESCENT AND \\ YOUNG ADULT FACT BOOK \\ BY THE CHILDREN'S DEFENSE FUND}

This comprehensive reference on America's 10- to 24-year olds describes in detail: family income, education of parents, where youths live, family types, health status, mortality, causes of death, school enrollment, educational attainment, sexual activity, childbearing, family formation, employment and earnings, drug and alcohol use, victimization, crime and more...

... all in one easy-to-use source book, which includes 113 tables and 30 graphs!

Today's youths are much like those of earlier generations. But the world around them has changed, and many are being left behind.

The young man who drops out of high school has little chance to earn a survival wage working with his hands. Today's teen mother is likely to be unmarried and at dire risk of poverty.

The Adolescent and Young Adult Fact Book reveals that poverty, lack of education, race, and gender are linked closely to troubling outcomes for youths.

For everyone who works with youths, or needs data and analyses for speeches, funding proposals, testimony, or research — don't miss this important book!

\section{THE ADOLESCENT AND YOUNG ADULT FACT BOOK}

Yes! Please send me copy/ies of CDF's The Adolescent and Young Adult Fact Book $(\$ 13.95$ per copy, including postage).

NAME

ADDRESS

CITY STATE ZIP

DAYTIME TELEPHONE

To Order: Please detach this form and mail in an envelope to: Children's Defense Fund Publications, 122 C Street N.W., Washington, D.C. 20001, (202) 628-8787. Orders under $\$ 25$ must be accompanied by payment. Orders over $\$ 25$ may be paid using:

(for orders over $\$ 25$ only)

VISA

MASTERCARD

CARD NUMBER EXPIRATION DATE: 
Children's Defense Fund

122 C Street, N.W.

Suite 400

Washington, D.C. 20001

Non-Profit Org.

- $\rightarrow$ GCV 